Article

\title{
Development and Evaluation of a New "Snow Water Index (SWI)" for Accurate Snow Cover Delineation
}

\author{
Abhilasha Dixit ${ }^{1, *(\mathbb{D})}$, Ajanta Goswami ${ }^{2}$ (D) and Sanjay Jain ${ }^{3}$ \\ 1 Centre of Excellence in Disaster Mitigation and Management, Indian Institute of Technology, \\ Roorkee-247667, India \\ 2 Department of Earth Sciences, Indian Institute of Technology, Roorkee 247667, India; ajanta.fes@iitr.ac.in \\ 3 Scientist G, National Institute of Hydrology, Roorkee 247667, India; sjain.nihr@gov.in \\ * Correspondence: adixit@dm.iitr.ac.in; Tel.: +91-9760757914
}

Received: 21 October 2019; Accepted: 12 November 2019; Published: 25 November 2019

check for updates

\begin{abstract}
The current study started by examining the three most established snow indices, namely the NDSI (normalized difference snow index), S3, and NDSII-1 (normalized difference snow and ice index), based on their capabilities to differentiate snow pixels from cloud, debris, vegetation, and water pixels. Furthermore, considering the limitations of these indices, a new spectral index called the snow water index (SWI) is proposed. SWI uses spectral characteristics of the visible, SWIR (shortwave infrared), and NIR (near infrared) bands to achieve significant contrast between snow/ice pixels and other pixels including water bodies. A three-step accuracy assessment technique established the dominance of SWI over NDSI, S3, and NDSII-1. In the first step, image thresholding using standard value $(>0)$, individual index theory (fixed threshold), histogram, and GCPs (ground control points) derived threshold were used to assess the performance of the selected indices. In the second step, comparisons of the spectral separation of features in the individual band were made from the field spectral observations collected using a spectroradiometer. In the third step, GCPs collected using field surveys were used to derive the user's accuracy, producer's accuracy, overall accuracy, and kappa coefficient for each index. The SWI threshold varied between 0.21 to 0.25 in all of the selected observations from both ablation and accumulation time. Spectral separability plots justify the SWI's capability of extraction and removal of the most critical water pixels in integration with other impure classes from snow/ice pixels. GCP enabled accuracy assessment resulted in a maximum overall accuracy (0.93) and kappa statistics (0.947) value for the SWI. Thus, the results of the accuracy assessment justified the supremacy of the SWI over other indices. The study revealed that SWI demonstrates a considerably higher correlation with actual snow/ice cover and is prominent for spatio-temporal snow cover studies globally.
\end{abstract}

Keywords: NDSI; SWI; NDSII-1; snow water index (SWI); remote sensing

\section{Introduction}

The Himalayas are known as the largest abode of snow and glaciers apart from the Arctic and Antarctic. Snow and glacier melt from the Himalayas sustain the perennial river flow in major river systems like the Indus, Ganga, and Brahmaputra. These river systems receive $30-50 \%$ of the annual flow from snow and glacier melt runoff [1-4]. Thus, directly and indirectly, snow and glacier melt occurring from the Himalayan region support irrigation and industrial water demand of a very large population residing in the Himalayas and the Indo-Gangetic alluvial plain. Studies have shown that the large accumulation of snow cover of the Himalayas influences the Earth's radiation budget on regional, local, and global scales [5-9]. According to Lu et al. [10], snow's distinct high surface reflectance and low thermal conductivity influence biological, chemical, and geological characteristics of earth soil 
cover. At local levels, it directly impacts different soil variables such as permeability, temperature, moisture, microbial activity, and carbon sequestration [11,12], while at the regional scale, it strongly influences plant composition and plant community structure $[13,14]$. Snow is also a sensitive index of climate change, which gives a direct measure of the sustainability of Himalayan biodiversity and a healthy eco-system.

Early researchers [15-21] working in the domain of snow climatology started mapping snow cover area with different ground-based and aerial photographic survey techniques. Ground-based monitoring methods were extremely labor-intensive, expensive, and potentially dangerous in tough and inaccessible river basins [22]. Therefore, field surveys are not suitable for the often-quick melting snow cover mapping in tough terrain conditions [10]. Instead of a field-based survey, aerial surveys are an easily accessible technique that provides much more comprehensive information in the short span of the survey time. The aerial survey has its own limitations in terms of processing time needed for executing a number of overlapped aerial images for large river basin areas, high aircraft operating costs, and difficulty in interpreting snow cover in forest shaded regions [23]. The launch of the TIROS-1 (Television Infrared Observation Satellite) satellite in 1960 pioneered the concept of multispectral remote sensing for snow and glacier hydrology. Since then, the potential of snow and ice cover mapping has been strengthened by the various advancements in high spatio-temporal frequency satellites and sensors [24-31]. Snow cover area information collected from satellite observations has been widely used for different studies related to climate change assessment and snowmelt runoff modeling.

The arrival of high-resolution remote sensing satellites has motivated different researchers [32-34] to exploit and review numerous digital information techniques and datasets (with different spatial and temporal resolution) to accurately map snow cover area on a regional and global scale. Indices are the most frequently used automated methods for snow/ice cover mapping. NDSI, S3, and NDSII-1 are some of the indices that provide the maximum separation between snow and different features such as ice, cloud, and vegetation [35-41] and manifest their significance in snow mapping on satellite data. These indices utilize the reflectance and absorptive properties of snow in visible, NIR, and SWIR bands [29,35,38-40,42-47].

Although these indices have been frequently used for snow cover mapping with various multispectral satellite datasets and proven their significance in extracting snow cover in different terrain conditions, water and cloud are two major impurities that pose as a challenge in extracting snow pixels from space-borne multispectral sensors. A series of studies have been conducted for developing a masking technique or improved indices [48-51] for removing the impact of cloud pixels, but there are a sufficient number of studies [29,37,52-56] that have shown that water pixels are always misunderstood as snow when extracted with these indices. Thus, there is an additional requirement of a filtering technique for precise delineation of snow cover with available index-based techniques.

In this study, we propose a new snow cover index named the snow water index (SWI). The SWI is developed with the spectral wavelengths of the visible, SWIR, and NIR band of Landsat- 8 satellite to achieve a significant contrast between snow/ice pixels and other pixels including water bodies. The snow cover extraction capability of SWI was compared with NDSI, S3, and NDSII-1 by using a detailed three step accuracy assessment technique. In the first step, the image thresholding using a standard value $(>0)$, individual index theory, histogram, and GCPs (ground control points) derived threshold are used to assess the performance of the selected indices over high-resolution Landsat-8 and Sentinel-2 satellite images for both the accumulation and ablation period for 2017 and 2019. A comparison of these thresholds helps to draw a visual perception regarding the performance of indices in the presence of both the mixed and pure snow cover classes. In order to perform ground validations, a field survey was conducted around the SASE (Snow and Avalanche Study Establishment), DRDO (Defense Research \& Development Organization) observatories at Bhang (2039 m), Solang $(2480 \mathrm{~m})$, and Dhundi $(3050 \mathrm{~m})$ in the Beas River basin using spectroradiometer and DGPS (differential global positioning system) instruments. In the second step of the accuracy assessment, comparisons of spectral separation of features in the individual band are made from the field spectral observations 
to evaluate the performance of the individual indices qualitatively. As the SWI was developed using the Landsat-8 spectral wavelength, the respective spectral wavelength of the selected bands (green $(0.53-0.59 \mu \mathrm{m})$, NIR $(0.85-0.88 \mu \mathrm{m})$, SWIR $(1.57-1.65 \mu \mathrm{m})$ ) are extracted from the full range of spectroradiometer observations. In the third step, GCPs collected using field surveys are used to derive the user's accuracy, producer's accuracy, overall accuracy, and kappa coefficient for each index. The results of the accuracy assessment justified the supremacy of the SWI over other indices. Overall, this research work analyzed and reviewed the accuracy of the three most frequently used and newly proposed snow cover indices under the presence of different features like vegetation, water, debris, and cloud.

\section{Material and Methods}

The methodology of the current study includes: selection of suitable study area, data collection (Satellite \& Field data), Application of snow cover indices, image thresholding (Standard, Literature based, histogram, Field based). Accuracy of each snow indices will be evaluated qualitatively and quantitatively based on spectroradiometer and GCPs (Ground Control Points) validation. All the processing was done using ArcGIS 10.3 (Environmental Systems Research Institute, California, CA, USA), ERDAS IMAGINE 2014, Imagine Photogrammetry, Hexagon Geospatial and MATLAB R2019a software packages.

\subsection{Test Area}

The Beas River basin of the Himachal Pradesh State of India was selected for the current research study. The locational map of the study area is presented in Figure 1. The selected study area is spread over 347 square $\mathrm{km}$ in between the spatial extent of $76.92 \mathrm{E}$ to $77.58 \mathrm{E}$ and $31.87 \mathrm{~N}$ to $32.46 \mathrm{~N}$. Being a part of the lower Indian Himalaya and catchment area of the River Beas, the selected study area is characterized by high precipitation, cold temperature, and mostly glaciated and snow-covered terrain. The relative humidity in the region remains around $80 \%$. The temperature falls between $1.6^{\circ} \mathrm{C}$ and $12{ }^{\circ} \mathrm{C}$. The average annual rainfall varies between $94.68 \mathrm{~mm}$ and $165.51 \mathrm{~mm}$, and the annual average snowfall varies between $45.75 \mathrm{~mm}$ to $305.00 \mathrm{~mm}$. The area is covered with thick forest cover, which constitutes mainly Chil (Pinus roxburghii), Blue pine (Pinus wallichiana), Ban oak (Quercus leucotrichophora), and Deodar (Cerdus deodara) with a variety of broad-leaved trees along with shrubs and grasses. The Snow and Avalanche Study Establishment (SASE) of the Defense Research and Development Organization (DRDO), India has its own snow-meteorological observatories at Bhang (2039 m), Solang $(2480 \mathrm{~m})$ and Dhundi $(3050 \mathrm{~m})$ in the Beas basin area for studying the varying hydro-meteorological and climatological conditions of the basin.

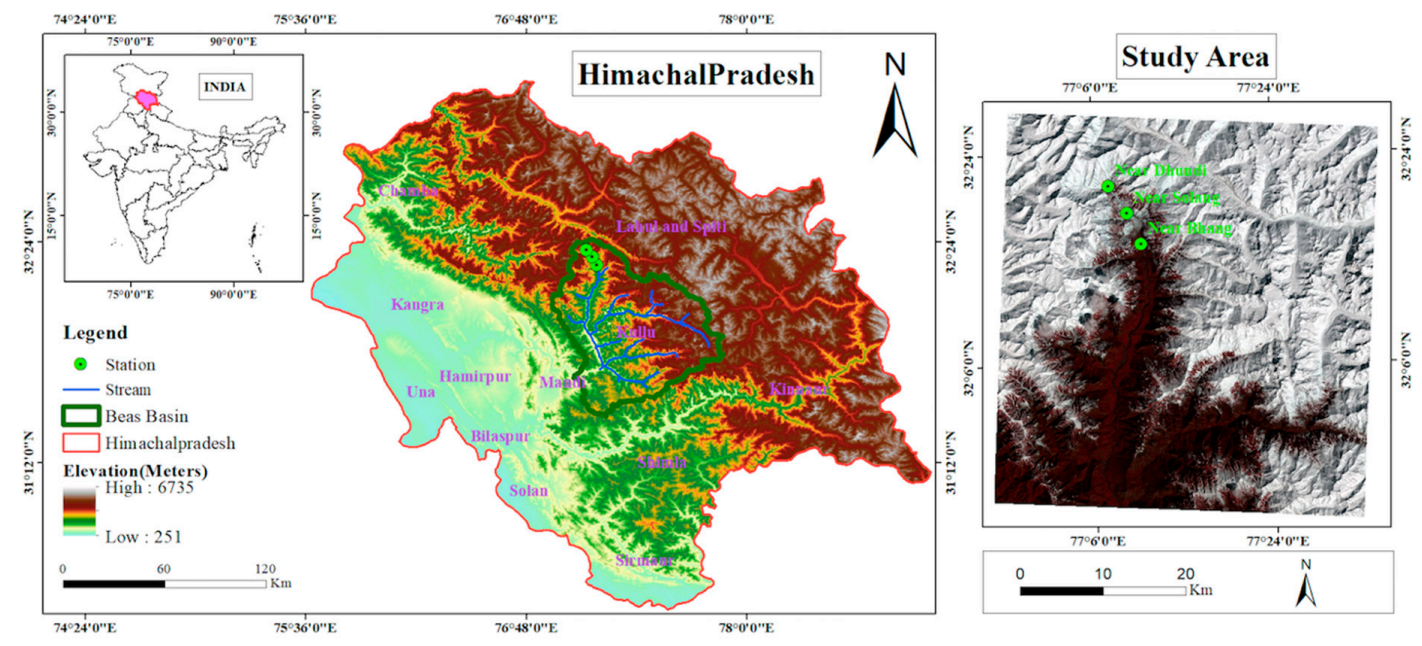

Figure 1. Location map of the study area. 


\subsection{Data Used}

In order to compare different existing snow cover mapping indices (NDSI, S3, and NDSII-1) with the proposed snow cover index (SWI) and evaluate their mapping accuracy, the current study used both the digital satellite image dataset and ground observations (spectroradiometer observations and ground control points).

\subsubsection{Digital Satellite Image Dataset}

Multi-spectral satellite imagery from Landsat-8 (OLI/TIRS) and Sentinel-2 satellites were the primary satellite datasets used for extracting snow cover in the current study. Two satellite images for the month of March and two satellite images for the month of September were downloaded for 2017 and 2019. Intentionally, satellite images with varying cloud cover percentages were selected to test the cloud detection and masking capability of the indices. Table 1 provides more information on the Landsat-8 and Sentinel-2 satellite image specifications. Both datasets were downloaded from the United States Geological Survey (USGS) Earth Explorer web portal [56].

Table 1. Specifications of Landsat-8 and Sentinel-2 satellite imagery.

\begin{tabular}{|c|c|c|c|}
\hline Sensor & Acquisition Date & Spectral Band with Wavelet $(\mu \mathrm{m})$ & Cloud Cover \\
\hline \multirow{8}{*}{ Landsat-8 } & 12 March 2017 & Costal (0.43-0.45) & $13.26 \%$ \\
\hline & 20 Sept 2017 & Blue (0.45-0.51) & $5 \%$ \\
\hline & 18 March 2019 & Green $(0.53-0.59)$ & $2.28 \%$ \\
\hline & & Red (0.63-0.67) & \multirow{5}{*}{$9 \%$} \\
\hline & & NIR (0.85-0.88) & \\
\hline & 10 Sept 2019 & SWIR-1 (1.57-1.65) & \\
\hline & & SWIR-2 (2.11-2.29) & \\
\hline & & Cirrus cloud (1.36-1.38) & \\
\hline \multirow{12}{*}{ Sentinel-2 } & 21 March 2017 & Costal (0.443) & $58 \%$ \\
\hline & 10 Sept 2017 & Blue (0.490) & $67 \%$ \\
\hline & 26 March 2019 & Green $(0.560)$ & $51.85 \%$ \\
\hline & & $\operatorname{Red}(0.665)$ & \\
\hline & & Vegetation red edge (0.705) & \multirow{8}{*}{$42 \%$} \\
\hline & & Vegetation red edge $(0.740)$ & \\
\hline & & Vegetation red edge (0.783) & \\
\hline & 17 Sept 2019 & NIR $(0.842)$ & \\
\hline & & Vegetation red edge (0.865) & \\
\hline & & SWIR-Cirrus (1.375) & \\
\hline & & SWIR-1 (1.610) & \\
\hline & & SWIR-2 (2.190) & \\
\hline
\end{tabular}

\subsubsection{Field Survey and Ground Observations}

Major ground observations were collected from 10 March to 30 March 2017 (morning 10:00 am to evening 4:00 pm) using spectroradiometer and differential GPS instruments around the SASE, DRDO laboratories at Bhang $(2039 \mathrm{~m})$, Solang $(2480 \mathrm{~m})$, and Dhundi $(3050 \mathrm{~m})$. Some observations were also collected near the Manali-Leh Highway while visiting the study area.

\section{Spectro-Radiometer Observations}

A complete spectroradiometer survey was carried out at various locations in the different land cover classes' proximity to all three observatories [57]. The spectral signatures of various ambient features such as snow, contaminated snow, forest cover, grassland, waterbody, etc., were gathered in the study area. Spectral reflectance was observed using a portable field spectroradiometer Field Spec Pro FR (Analytical Spectral Devices 1999), in the wavelength range of 350-2500 nm (3 nm spectral resolution in the VIR (visible infrared) and 10-12 nm spectral resolution range for SWIR (Analytical Spectral Devices 1999)). In this wavelength range, it collects radiometric measures such as radiance, 
reflectance, and irradiance. This experiment was conducted on a small area of $10 \mathrm{~m} \times 10 \mathrm{~m}$ plain ground. The obstruction-free coverage instrument was attached on a $2 \mathrm{~m}$ long metallic beam from the surface. For this study, the field of view was $25^{\circ}$, and the radiometer was set to nadir viewing over the target. The duration of spectral collection for each object was set to 10-15 minutes to evade the effect of environmental influences procured through changing the sun-sensor viewing geometry and physical/meteorological conditions. Figure 2 shows the spectral response of different features captured with a spectroradiometer from the selected study area.

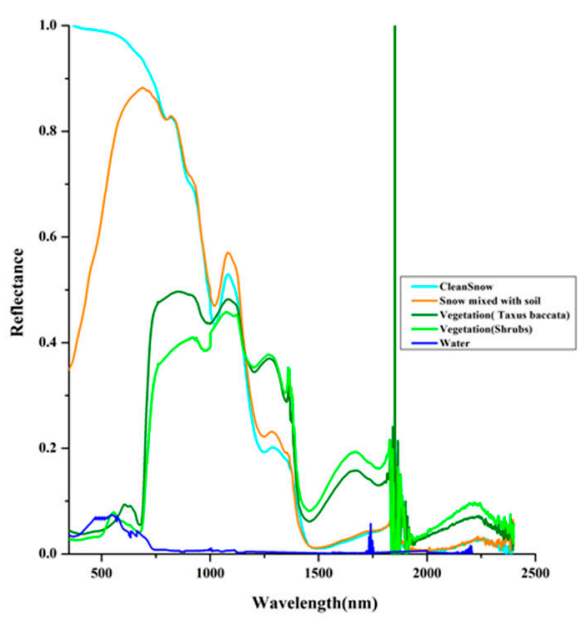

(a)

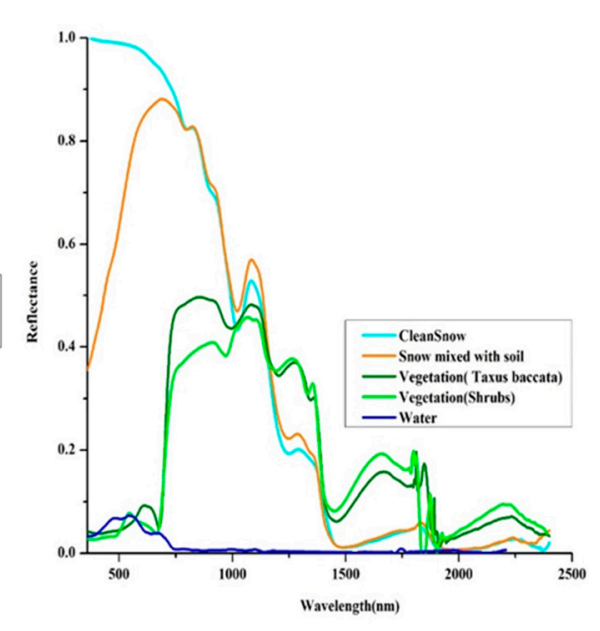

(b)

Figure 2. (a) Raw and (b) average values of the spectral signature of various features collected by a spectroradiometer.

\section{Ground Control Points (GCPs)}

The aim of the ground control points (GCPs) was to quantitatively assess how effectively the pixels were sampled into the correct land cover classes in different indices. Moreover, the key emphasis for ground control point selection was on areas that could be clearly identified on both Landsat- 8 and Sentinel-2 high-resolution images for both seasons in both years. A total of 30 ground control points (locations) were collected on the way to the Leh-Manali Highway and around three observatories of SASE, DRDO using a 'Trimble R7/5700' dual-frequency differential GPS instrument. Aside from the DGPS observations, an additional 194 points were marked over Google Earth Pro ${ }^{\mathrm{TM}}$ based on the field verifications and expert's knowledge of the area. These points were categorized in the respective class of land cover as snow, water, debris, forest, and grassland. Figure 3 presents both the actual field observations of the DGPS survey and additionally marked GCPs for the current study area. Figure 4 presents the field photographs depicting different land cover classes from the Beas River basin. Table 2 describes the number of DGPS points and Google Earth enabled GCPs for individual land cover class.

Table 2. DGPS (Differential Global Positioning System) and Google Earth enabled GCPs (Ground Control Points) collected for different land cover classes.

\begin{tabular}{ccc}
\hline Land Cover Class & No. of GCPs (DGPS Survey) & No. of GCPs (Google Earth) \\
\hline Snow & 10 & 44 \\
Water & 5 & 41 \\
Debris & 5 & 26 \\
Forest & 5 & 25 \\
Grassland & 5 & 28 \\
\hline
\end{tabular}




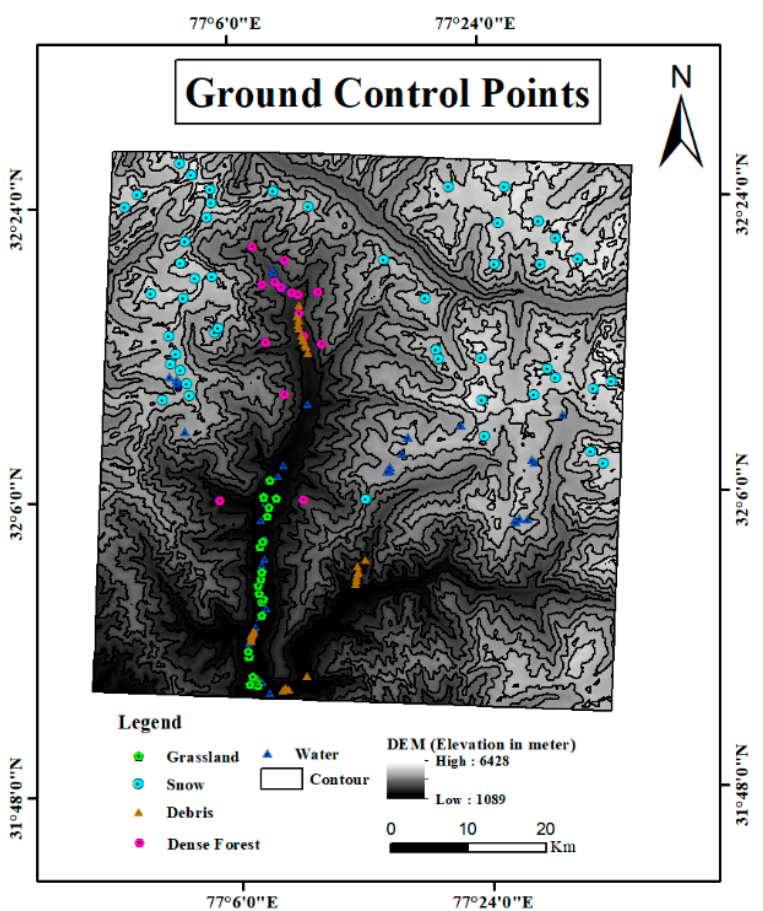

Figure 3. The distribution of GCPs (ground and Google Earth observations) in the study area.

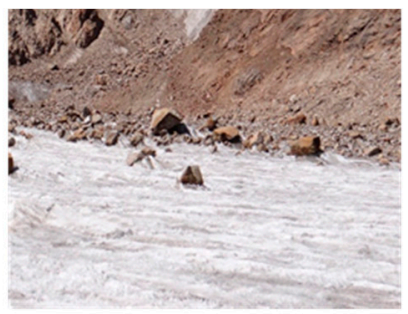

(a)

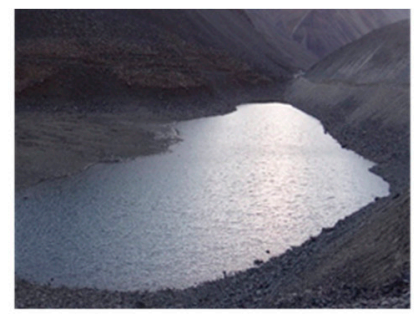

(b)

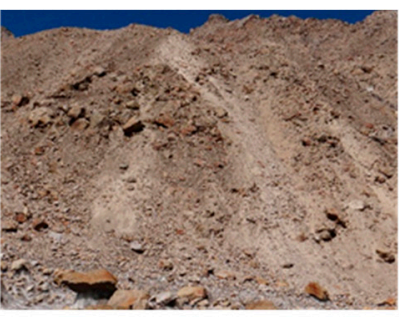

(c)

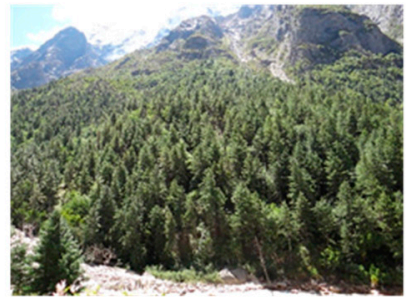

(d)

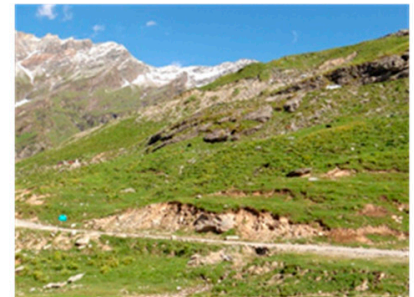

(e)

Figure 4. Field photograph (a) Snow (b) Water (c) Debris (d) Forest and (e) Grassland land cover features present in the selected study area.

\subsection{Methodology}

\subsubsection{Normalized Difference Snow Index (NDSI)}

NDSI is an automated approach that relies on the ratio of visible and short-wave infrared wavelengths to separate snow/ice pixels from cloud cover and other unwanted feature classes. The development of NDSI is the continuous efforts of utilizing the spectral information by different researchers to regionally [44] and globally [29] map the snow/ice features. As the snow depicts the highest reflectance in the green $0.545-0.565 \mu \mathrm{m}$ (visible) band and the lowest reflectance in the SWIR $1.628-1.652 \mu \mathrm{m}$ band $[29,44,56,58-61]$, the NDSI utilizes the ratio between the spectral characteristics of snow in visible and SWIR region. 
The mathematical representation of NDSI is presented in Equation (1).

$$
N D S I=\frac{(\text { Green }-S W I R)}{(\text { Green }+ \text { SWIR })}
$$

NDSI not only divides the wavelength range between snow and non-snow, but also helps to reduce the effect of cumulus clouds [57], atmospheric inferences, and geometric distortions [62]. Another advantage of NDSI is that it can take care of topographic effects [61], as it can potentially delineate and map snow under mountainous shadows [55]. Although NDSI ranges in between -1 to +1 , but various studies have suggested that a fixed threshold of 0.40 is optimum for snow cover mapping [29].

\subsubsection{S3 Index}

Saito and Yamazaki proposed S3 as an improved snow mapping indices in 1999 at the same time as when NDSI was developed. In 2006, Shimamura [38] assessed the accuracy of S3 over NDSI, specifically in the areas where snow cover and forested areas overlapped each other. The S3 index was originally designed for the GLI (Global Imager) sensor of ADEOS-II (Advanced Earth Observing Satellite II), launched in December 2002. Some studies have been conducted by researchers using the ADEOS-II sensor for measuring the efficiency of S3 in snow cover mapping [63-65]. As ADEOS-II stopped working in October 2003, various researchers have used Landsat ETM+ in different regions of the world and found that $\mathrm{S} 3$ has the capability to accurately map snow cover under dense forested areas without any reference data (NDVI). The reflectance of snow is high in the visible region, while in the case of vegetation, the reflectance increases from the red edge to the NIR (near infrared) wavelength. However, in the area where snow is found under vegetation cover, the reflection of snow and vegetation becomes mixed. Therefore, avoiding the effect of pixels holding both the snow and vegetation values on snow cover mapping, S3 uses the reflectance characteristics of snow in the red, NIR, and SWIR wavelengths $[38,57]$. In the Landsat- 8 satellite, near-infrared, red, and SWIR bands correspond to band $5(0.85$ to $0.89 \mu \mathrm{m})$, band $4(0.63$ to $0.68 \mu \mathrm{m})$, and band $6(1.56$ to $1.66 \mu \mathrm{m})$, respectively. The mathematical formulation of $\mathrm{S} 3$ is represented by Equation (2):

$$
S 3=\frac{N I R(R e d-S W I R)}{(N I R+R e d)(N I R+S W I R)}
$$

From various studies $[38,57,61,65]$, it was found that the threshold value of the S3 index is greater than 0.18 . In the case of snow-covered area and for snow under vegetation, the threshold value ranges from $0.05-0.18$.

\subsubsection{Normalized Difference Snow and Ice Index (NDSII-1)}

NDSII-1 was specially designed by Xiao et al. in 2001 for the VGT (Vegetation) sensor of the SPOT4 satellite, which was launched in 1998 for mapping snow and ice cover. The VGT sensor has four spectral bands (blue, red, near-infrared, and mid-infrared) equivalent to the Landsat TM bands. The NDSII-1 based VGT approach is a simple and automatic way of monitoring and mapping snow and ice cover areas from landscapes to global scales. The concept behind the development of the NDSII-1 index is to use the different aspects of snow reflectance in the red and SWIR bands of the VGT sensor. Landsat TM has the same spectral bands as VGT, so researchers have applied the NDSII-1 using Landsat TM on different regions of the world and compared it to the NDSI, where they found that NDSII-1 produced the same results as NDSI $[29,58]$. The mathematical representation of NDSII-1 is given by Equation (3):

$$
N D S I I=\frac{(\operatorname{Red}-S W I R)}{(\operatorname{Red}+S W I R)}
$$

The NDSII- 1 index ranges from -1 to +1 and also adopts a fixed 0.4 threshold value similar to the NDSI [39]. 


\subsubsection{Snow Water Index (SWI)}

Snow cover mapping over rugged terrain area with highly variable physical and meteorological conditions often suffers from the problem of snow-shadow mixing, snow-cloud mixing, snow-debris mixing, snow-vegetation mixing, and snow-water mixing. Thus, precise extraction and mapping of the snow-covered area in mountainous regions need proficient tools that are not affected by the other neighboring land cover variables, particularly water. In order to achieve more accurate snow cover mapping, in the current study, we proposed a new index named as SWI. This newly proposed index uses the combination of green, NIR, and SWIR bands and analyzes the spectral characteristics of snow, cloud, vegetation, and especially water in these regions. Similar to earlier indices, the SWI is capable of eliminating the impact of prominent neighborhood classes like cloud, soil, vegetation, and water. An extension to earlier indices, this index has a more sophisticated way of eliminating the influence of neighboring water pixels. The water feature shows higher reflectance in the green wavelength region and absorbs the maximum radiation in the NIR region. The absorptive property of water in the NIR region makes it possible to easily discriminate snow from water $[29,52,53,55,56]$. Therefore, to create a significant contrast between snow and other features, especially in the case of water, the SWI achieves the maximum accuracy. The mathematical representation of the snow water index (SWI) is given by Equation (4):

$$
S W I=\frac{\text { Green }(N I R-S W I R)}{(\text { Green }+ \text { NIR })(N I R+S W I R)}
$$

The high reflective property of the cloud in the green as well in the SWIR bands makes it possible to distinguish it from snow easily. SWI uses the snow and vegetation reflectance characteristics in the green and NIR wavelength region to accurately map the snow under vegetation. The ratio of (green/green + NIR) is used for reducing the impact of vegetation on snow. One of the major advantages of SWI is the ratio of (NIR - SWIR/NIR + SWIR), which works as a water mask. Snow cover area extraction and mapping from SWI alone delivered better performance and accuracy when compared to the NDSI, S3, and NDSII-1. From the various observations, it was found that the threshold value of the SWI index for the snow cover area was greater than 0.21 .

\subsection{Accuracy Assessment}

One of the most critical and vital steps of a snow indices comparison study is accuracy assessment. Even though the purpose of the indices is to produce fast and accurate water maps, an accuracy assessment must be conducted for evaluation purposes.

\subsubsection{Index Thresholding}

In this first part of the accuracy assessment, the performance of snow indices for Landsat- 8 and Sentinel-2 satellites was assessed using image thresholding. Image thresholding is a process of deciding a partitioning value that transforms a grayscale image into a binary segmented output image. There are different ways of finding out a threshold value for an index like the standard value $(>0)$, individual index theory (fixed threshold), histogram, and GCPs. In the current study, all of these threshold values were derived for each of the studied indices, and their snow cover delineation capability was evaluated for all of the input satellite images. A comparison of these thresholds will help to draw a visual perception regarding the performance of indices in the presence of both the mixed and pure snow cover classes. A detailed comparison and discussion of the resultant binary (snow/non-snow) image will be conducted to evaluate the performance of each index.

\subsubsection{Spectro-Radiometer Validation}

Spectral response of the ASD spectroradiometer $(350-2500 \mathrm{~nm}$ ) is one of the primary inputs of the proposed accuracy assessment technique. This dataset is used for measuring the reflectance of snow under the presence of different features (i.e., cloud, soil, vegetation, water) in the green, red, 
NIR, and SWIR wavelengths. Reflectance observations in satellite imagery as well as ground truth dataset in the green $(0.53-0.59 \mu \mathrm{m})$, red $(0.63-0.67 \mu \mathrm{m}), \operatorname{NIR}(0.85-0.88 \mu \mathrm{m})$, and SWIR $(1.57-1.65 \mu \mathrm{m})$ wavelengths used for computing the selected indices for snow cover estimation. The accuracy of each index was decided by the spectral separation plot of various features in the individual wavelengths with respect to the snow cover indices. The performances of NDSI, S3, and NDSII-1, specifically over water features, were spectrally studied to delineate the accuracy of snow cover estimation.

\subsubsection{GCPs (Ground Control Points) Validation}

Accuracy assessment is a vital step for feature identification and mapping projects. It compares the classified image to the ground control point datasets reflecting the actual ground truth values with reference to the selected feature class [66-69]. There are four different indicators of a ground truth based accuracy assessment for any classification project.

User Accuracy (UA): The ratio between the number of correctly classified pixels and the classified total pixels of the particular feature class is the user's accuracy [66-68].

Producer's Accuracy (PA): The ratio between the number of correctly classified pixels and the reference total pixels for a particular feature class is called the producer's accuracy [66-68].

Overall Accuracy (OA): Overall accuracy of a classified image represents the ratio of the total number of accurately identified pixels and total number of pixels in the image [66-68].

Kappa Statistics: Kappa statistics are a representation of how closely the image pixels classified by the indexing technique matched the data labelled as ground truth, controlling for the accuracy of a random classifier as measured by the expected accuracy $[68,69]$.

\section{Results and Discussion}

In this section, the performance of various snow indices for snow identification and mapping for the selected satellite images is evaluated. First, an assessment of each index will be conducted for the standard, literature based (fixed threshold), histogram, and GCPs thresholds, then a spectral relationship is established between the indices and various classes' reflectance in the green, red, NIR and SWIR regions using spectroradiometer observations. Finally, GCPs enabled assessment of the user's, producer's, overall accuracy, and kappa parameters of the different snow indices will be conducted to evaluate the performance. A detailed comparison and discussion of the different snow indices are vital to achieve a more accurate snow cover extraction technique.

\subsection{Image Thresholding and Snow/Non-Snow Classification}

Using the equations of the individual indices (Equations (1)-(4) and satellite images from 2017 and 2019 for both the accumulation and ablation time period (Figure 5), 64 index maps were derived. For each scene, to achieve a binary classification snow/non-snow map, different image thresholds were selected. First, a standard threshold $(>0)$ was selected for all indices. Then, the literature review for the individual indices was undertaken, and their theoretical threshold values were identified. Then, a conventional approach of histogram thresholding was assessed, and the threshold was identified. Figure 6 presents the NDSI frequency distribution-based histogram thresholding for the accumulation and ablation time of 2017. Landsat- 8 satellite images were processed with MATLAB software, and the histogram was prepared for both images. This histogram was examined with a trial and error-based approach for estimating the minimum, maximum, and optimal threshold value with reference to the true image. Similar to the NDSI image, thresholding was performed for all of the selected indices. Finally, based on the ground validation dataset (GCPs), threshold values were extracted for each index. All of these threshold values for 2017 and 2019 are presented in Tables 3 and 4, respectively. 


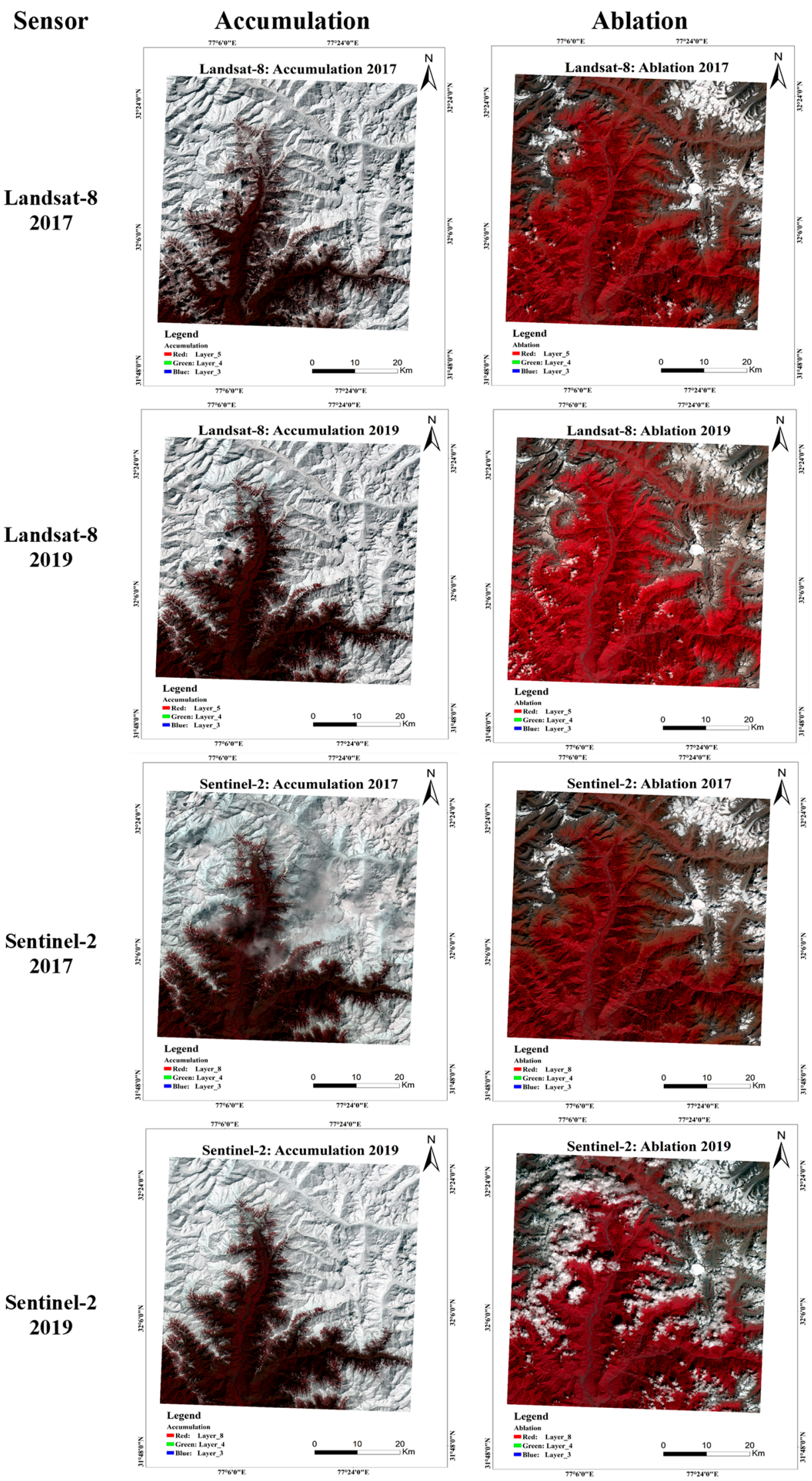

Figure 5. Landsat- 8 and Sentinel-2 satellite images for the accumulation and ablation period. 


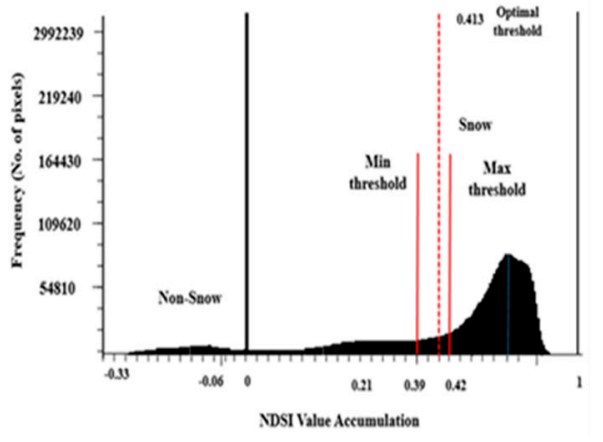

(a)

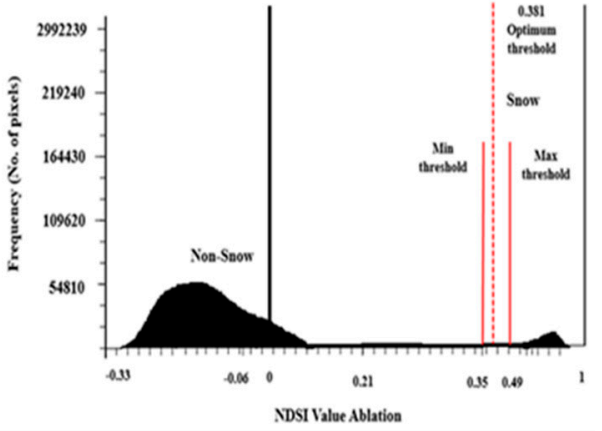

(b)

Figure 6. NDSI frequency distribution based histogram thresholding (a) Accumulation and (b) Ablation time period (Landsat-8 2017 images) satellite images.

Table 3. Selected standard, literature review based, histogram enabled, and GCPs computed threshold values for different snow indices in the satellite images for 2017.

\begin{tabular}{|c|c|c|c|c|c|c|c|}
\hline \multirow{2}{*}{ Sensor } & \multirow{2}{*}{$\begin{array}{l}\text { Snow } \\
\text { Indices }\end{array}$} & \multirow{2}{*}{$\begin{array}{l}\text { Standard } \\
\text { Threshold }\end{array}$} & \multirow{2}{*}{$\begin{array}{c}\text { Literature } \\
\text { Based Threshold }\end{array}$} & \multicolumn{2}{|c|}{ Histogram Based Threshold } & \multicolumn{2}{|c|}{ Field Based Threshold } \\
\hline & & & & Accumulation & Ablation & Accums & blation \\
\hline \multirow{4}{*}{$\begin{array}{l}\text { Landsat-8 } \\
2017\end{array}$} & NDSI & $>0$ & 0.40 & $0.40-0.42$ & $0.35-0.49$ & 0.38 & 0.40 \\
\hline & NDSII & $>0$ & 0.40 & $0.38-0.42$ & $0.34-0.43$ & 0.40 & 0.39 \\
\hline & S3 & $>0$ & 0.18 & $0.18-0.24$ & $0.12-0.23$ & 0.19 & 0.19 \\
\hline & SWI & $>0$ & $\begin{array}{c}0.18 \text { (Took same } \\
\text { as S3) }\end{array}$ & $0.20-0.24$ & $0.20-0.27$ & 0.22 & 0.23 \\
\hline \multirow{4}{*}{$\begin{array}{l}\text { Sentinel-2 } \\
2017\end{array}$} & NDSI & $>0$ & 0.40 & $0.37-0.56$ & $0.35-0.55$ & 0.45 & 0.42 \\
\hline & NDSII & $>0$ & 0.40 & $0.35-0.42$ & $0.35-0.49$ & 0.39 & 0.42 \\
\hline & S3 & $>0$ & 0.18 & $0.17-0.22$ & $0.15-0.21$ & 0.18 & 0.22 \\
\hline & SWI & $>0$ & $\begin{array}{c}0.18 \text { (Took same } \\
\text { as S3) }\end{array}$ & $0.19-0.23$ & $0.24-0.28$ & 0.21 & 0.23 \\
\hline
\end{tabular}

Table 4. Selected standard, literature review based, histogram enabled, and GCPs computed threshold values for different snow indices in the satellite images for 2019.

\begin{tabular}{|c|c|c|c|c|c|c|c|}
\hline \multirow{2}{*}{ Sensor } & \multirow{2}{*}{$\begin{array}{l}\text { Snow } \\
\text { Indices }\end{array}$} & \multirow{2}{*}{$\begin{array}{l}\text { Standard } \\
\text { Threshold }\end{array}$} & \multirow{2}{*}{$\begin{array}{c}\text { Literature } \\
\text { Based Threshold }\end{array}$} & \multicolumn{2}{|c|}{ Histogram Based Threshold } & \multicolumn{2}{|c|}{ Field Based Threshold } \\
\hline & & & & Accumulation & Ablation & Accums & blation \\
\hline \multirow{4}{*}{$\begin{array}{l}\text { Landsat- } 8 \\
2019\end{array}$} & NDSI & $>0$ & 0.40 & $0.39-0.41$ & $0.31-0.47$ & 0.41 & 0.43 \\
\hline & NDSII & $>0$ & 0.40 & $0.39-0.41$ & $0.31-0.47$ & 0.38 & 0.42 \\
\hline & S3 & $>0$ & 0.18 & $0.17-0.21$ & $0.16-0.25$ & 0.17 & 0.21 \\
\hline & SWI & $>0$ & $\begin{array}{c}0.18 \text { (Took same } \\
\text { as S3) }\end{array}$ & $0.18-0.25$ & $0.19-0.27$ & 0.20 & 0.23 \\
\hline \multirow{4}{*}{$\begin{array}{l}\text { Sentinel-2 } \\
2019\end{array}$} & NDSI & $>0$ & 0.40 & $0.41-0.53$ & $0.45-0.53$ & 0.43 & 0.46 \\
\hline & NDSII & $>0$ & 0.40 & $0.49-0.52$ & $0.43-0.51$ & 0.43 & 0.47 \\
\hline & S3 & $>0$ & 0.18 & $0.16-0.26$ & $0.21-0.30$ & 0.20 & 0.20 \\
\hline & SWI & $>0$ & $\begin{array}{c}0.18 \text { (Took same } \\
\text { as S3) }\end{array}$ & $0.22-0.29$ & $0.22-0.29$ & 0.24 & 0.22 \\
\hline
\end{tabular}

Once the two-decimal threshold was decided for all indices for all of the selected satellite scenes, a binary classification was performed to partition the images into two classes, namely, snow and non-snow. Figures 7-14 present the binary snow/non-snow images for all of the selected test scenes. In all of these figures, the first row of the figures representing NDSI maps, second row represents NDSII-1 maps, the third row shows S3 maps, and the fourth row represents SWI (proposed index) maps. Classes other than snow are highlighted to understand the impact of indices. Red rectangles are used to demarcate the flowing water features like the river, pink rectangles are drawn over static water bodies like lakes, and yellow rectangles are used to represent cloud-covered regions. The blue color in the legend represents snow pixels, and grey pixels show non-snow pixels. 


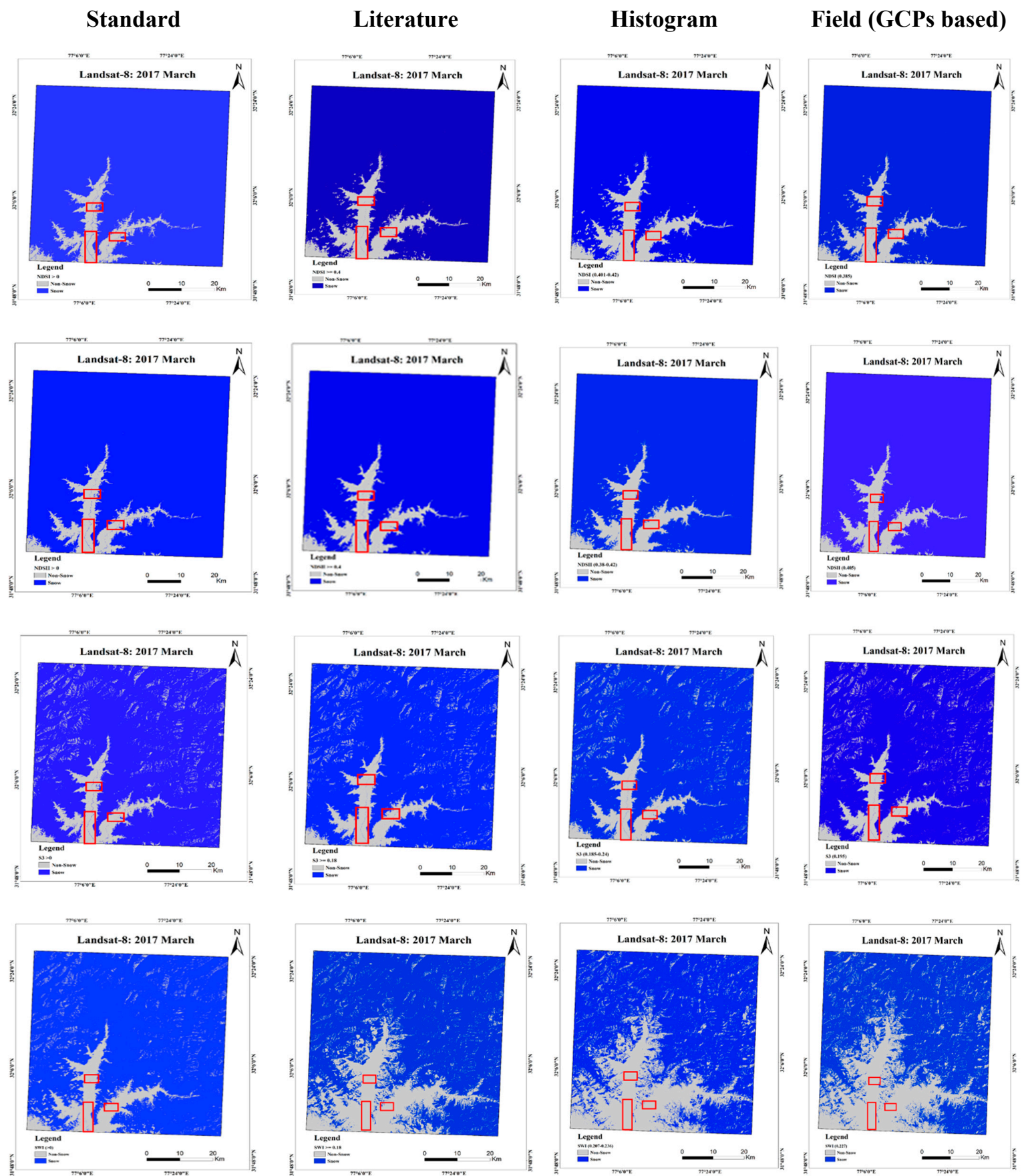

Figure 7. Snow classification output for different snow indices with the standard, literature, histogram, and GCPs driven thresholds for the March 2017 Landsat-8 image. 


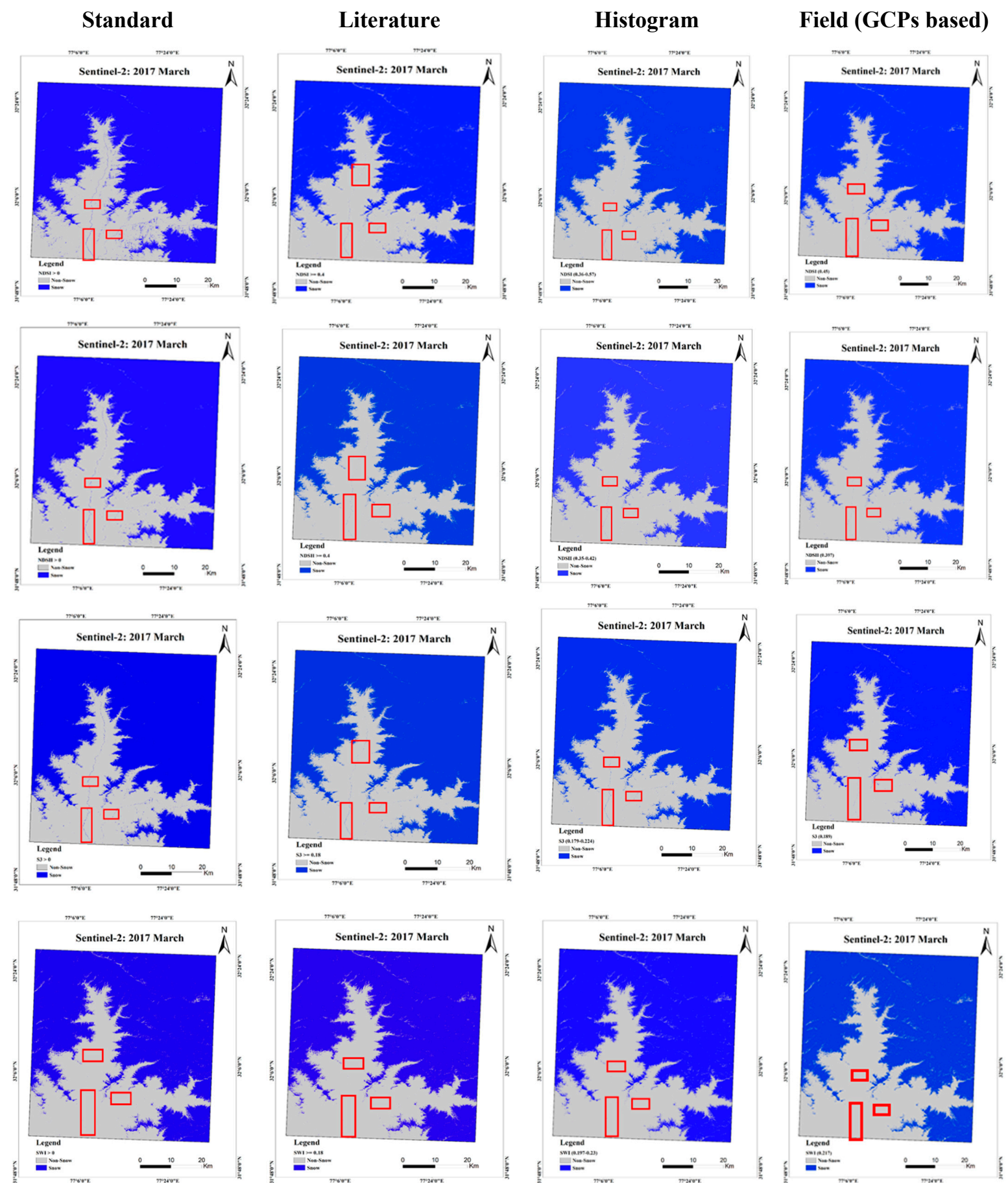

Figure 8. Snow classification output for different snow indices with the standard, literature, histogram, and GCPs driven thresholds for the March 2017 Sentinel-2 image. 

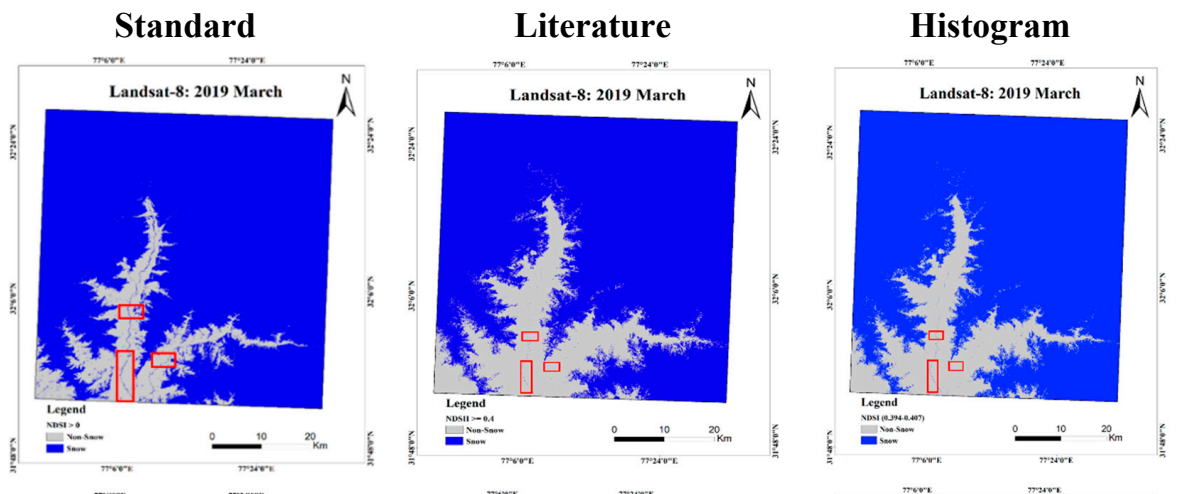

Field (GCPs based)
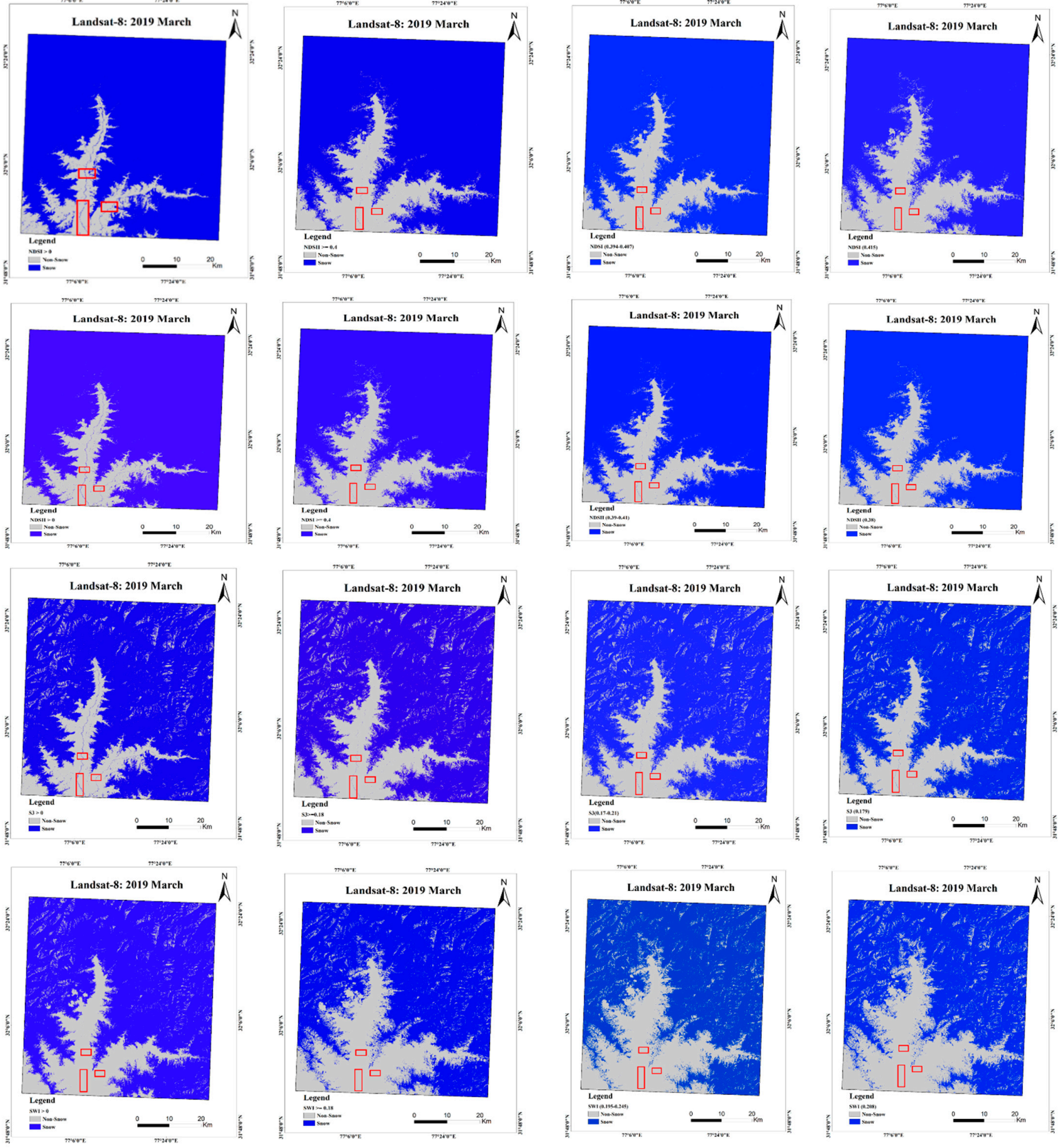

Figure 9. Snow classification output for different snow indices with the standard, literature, histogram and GCPs driven thresholds for the March 2019 Landsat-8 image. 


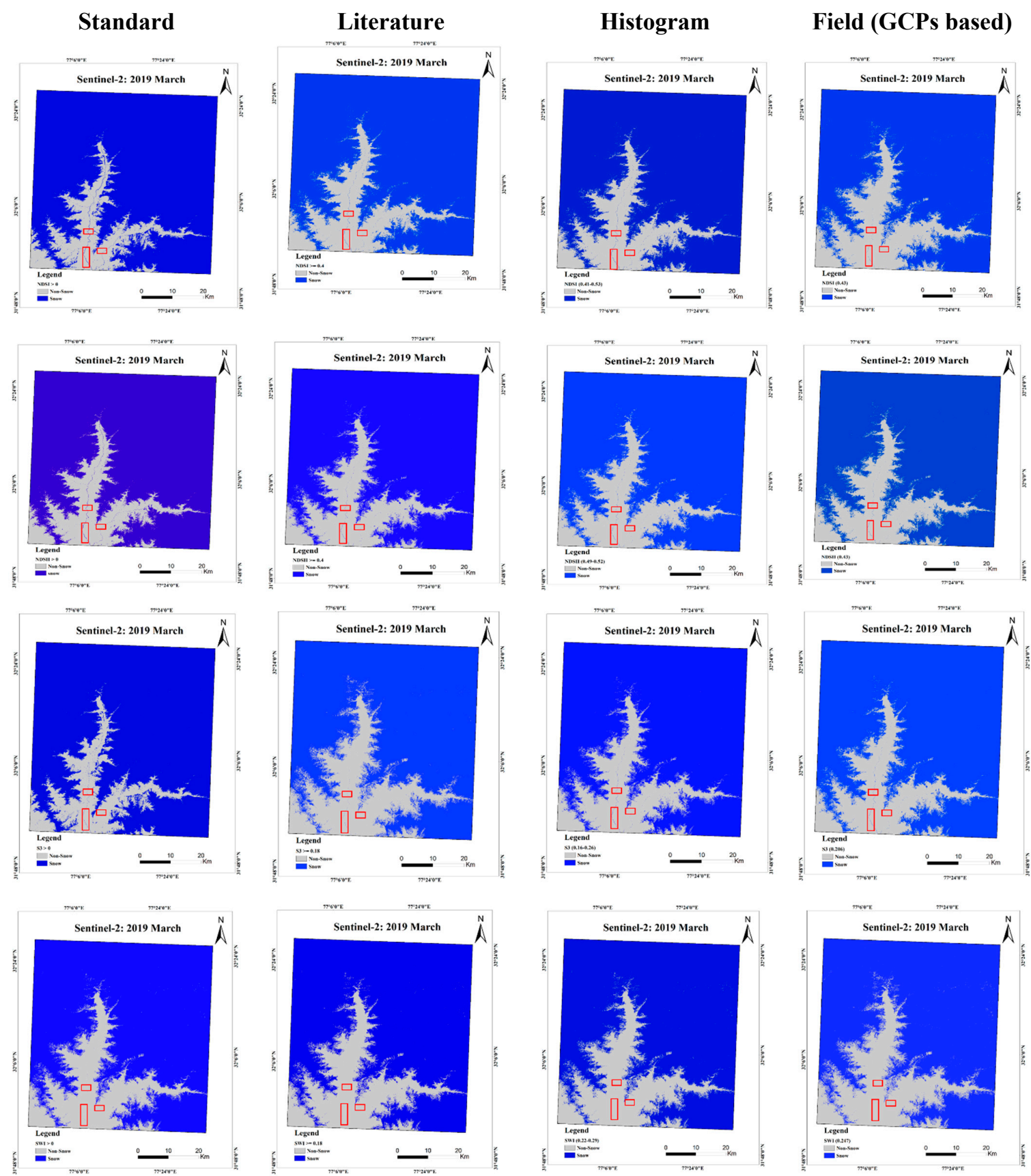

Figure 10. Snow classification output for different snow indices with the standard, literature, histogram, and GCPs driven thresholds for the March 2019 Sentinel-2 image. 


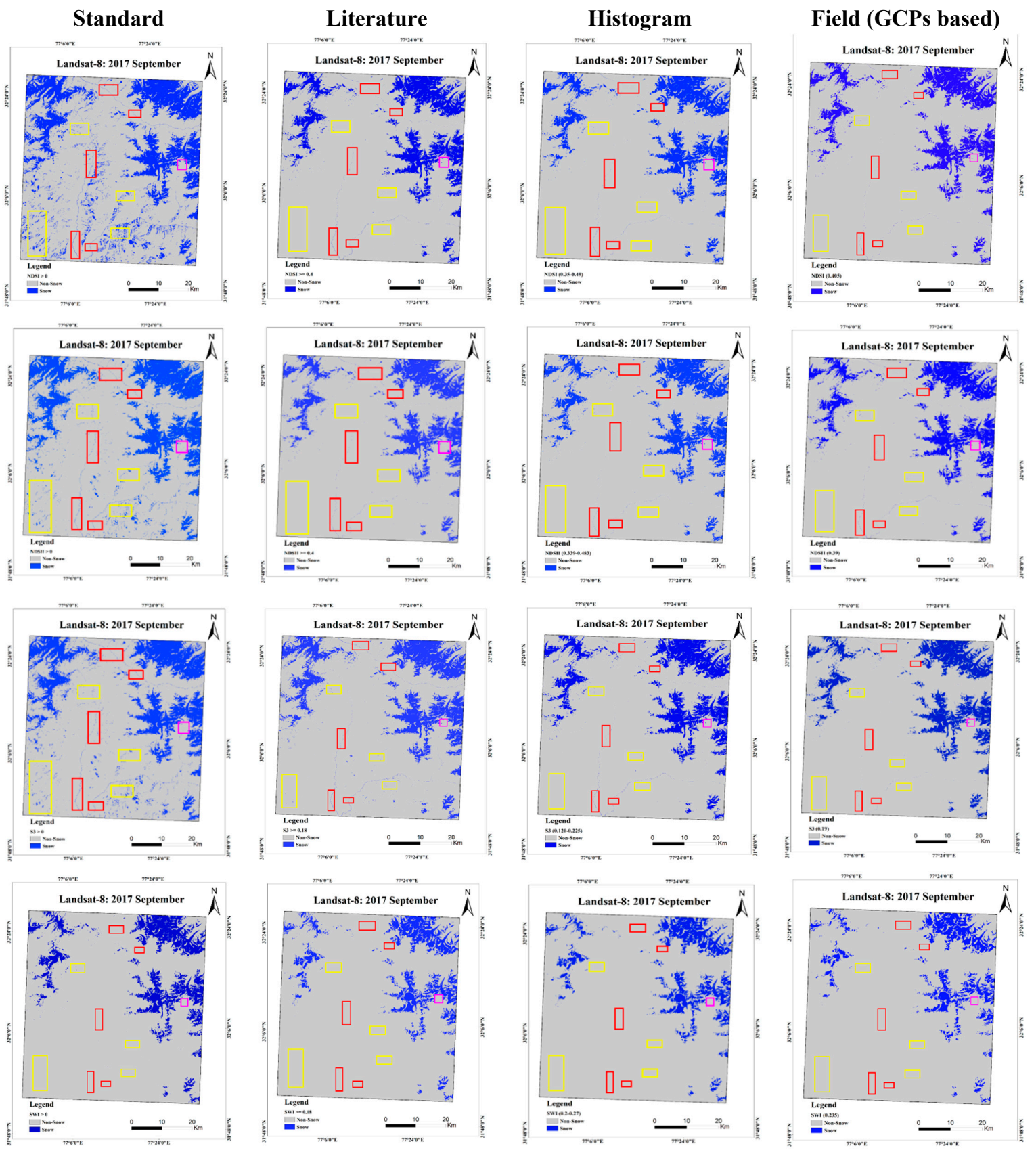

Figure 11. Snow classification output for different snow indices with the standard, literature, histogram, and GCPs driven thresholds for the September 2017 Landsat-8 image. 


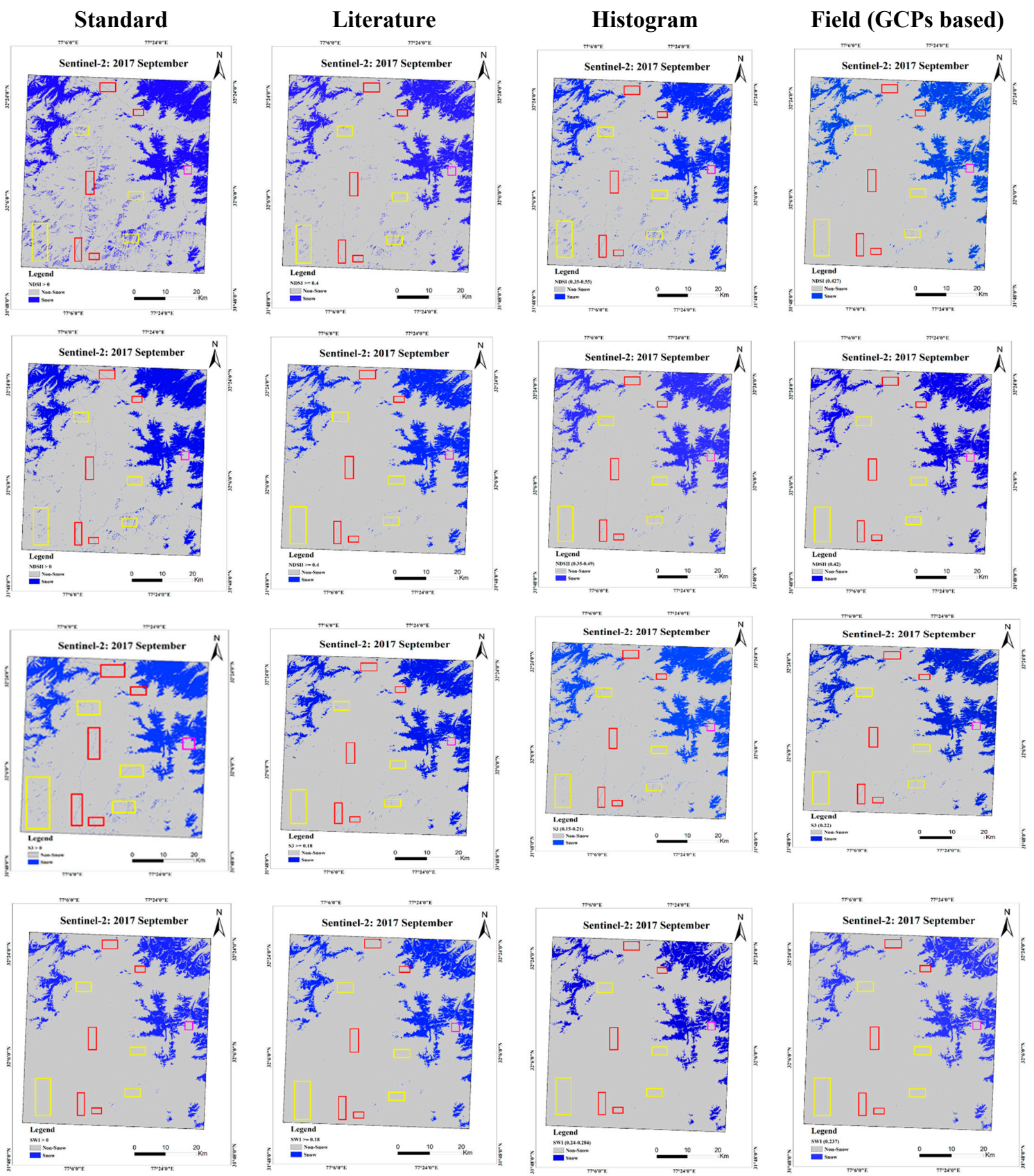

Figure 12. Snow classification output for different snow indices with the standard, literature, histogram, and GCPs driven thresholds for the September 2017 Sentinel-2 image. 

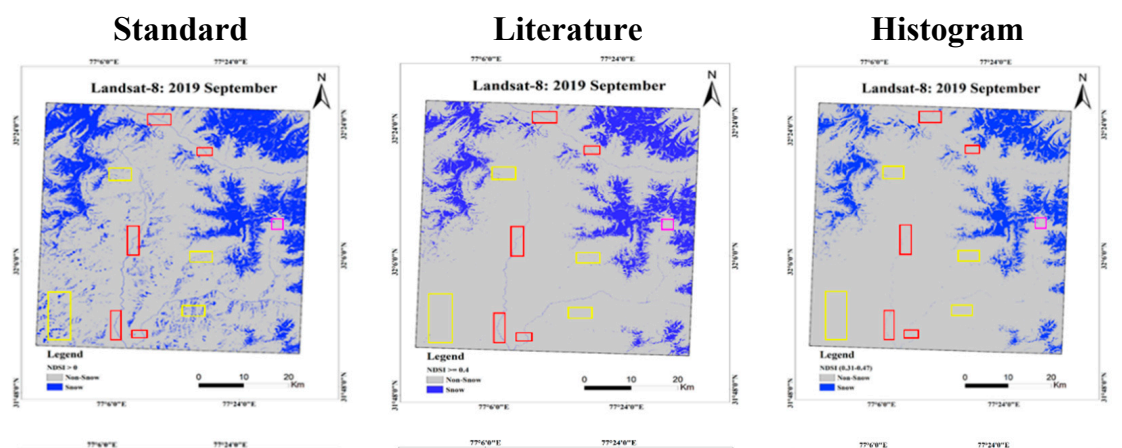

Field (GCPs based)
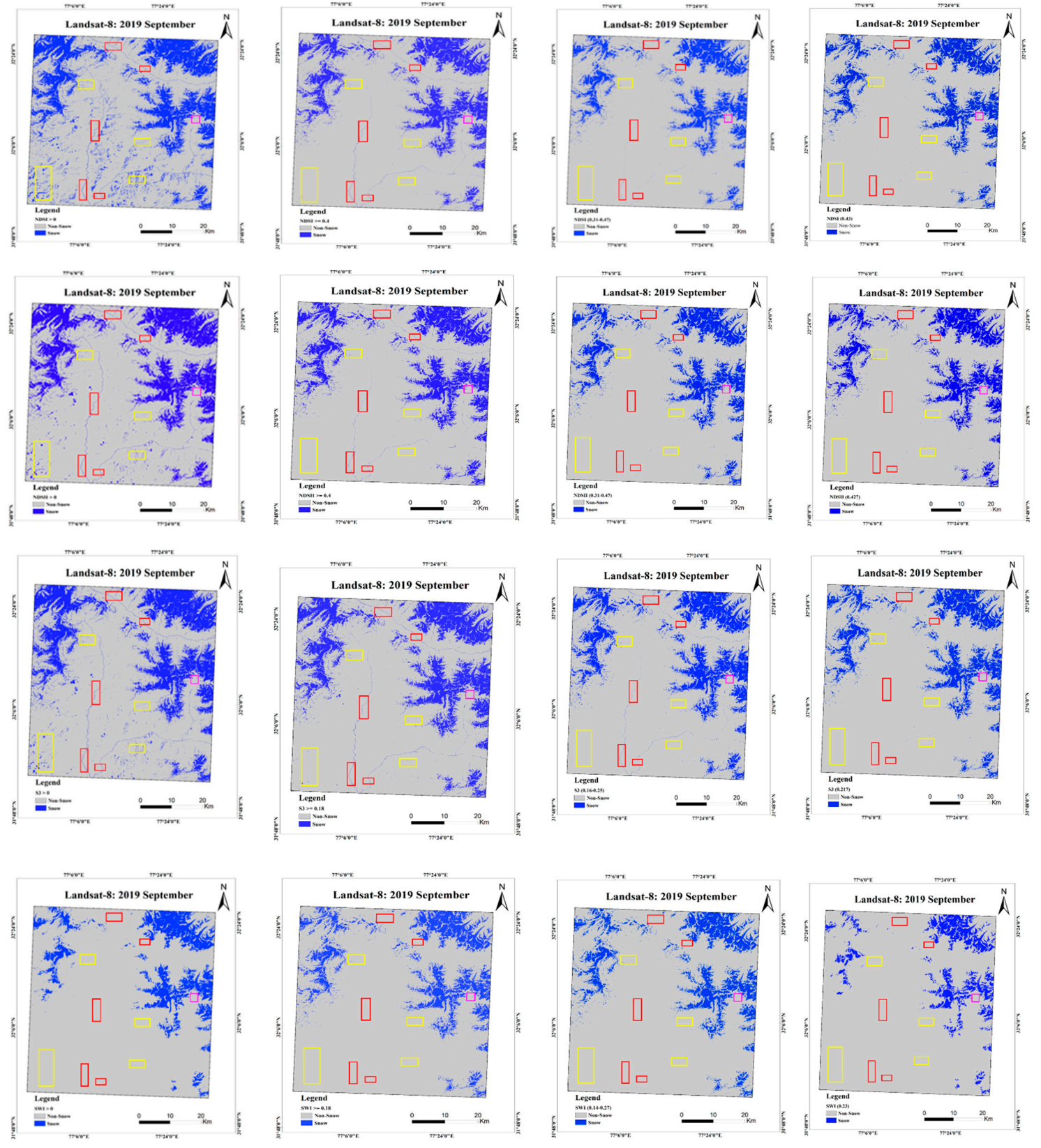

Figure 13. Snow classification output for different snow indices with the standard, literature, histogram, and GCPs driven thresholds for the September 2019 Landsat- 8 image. 


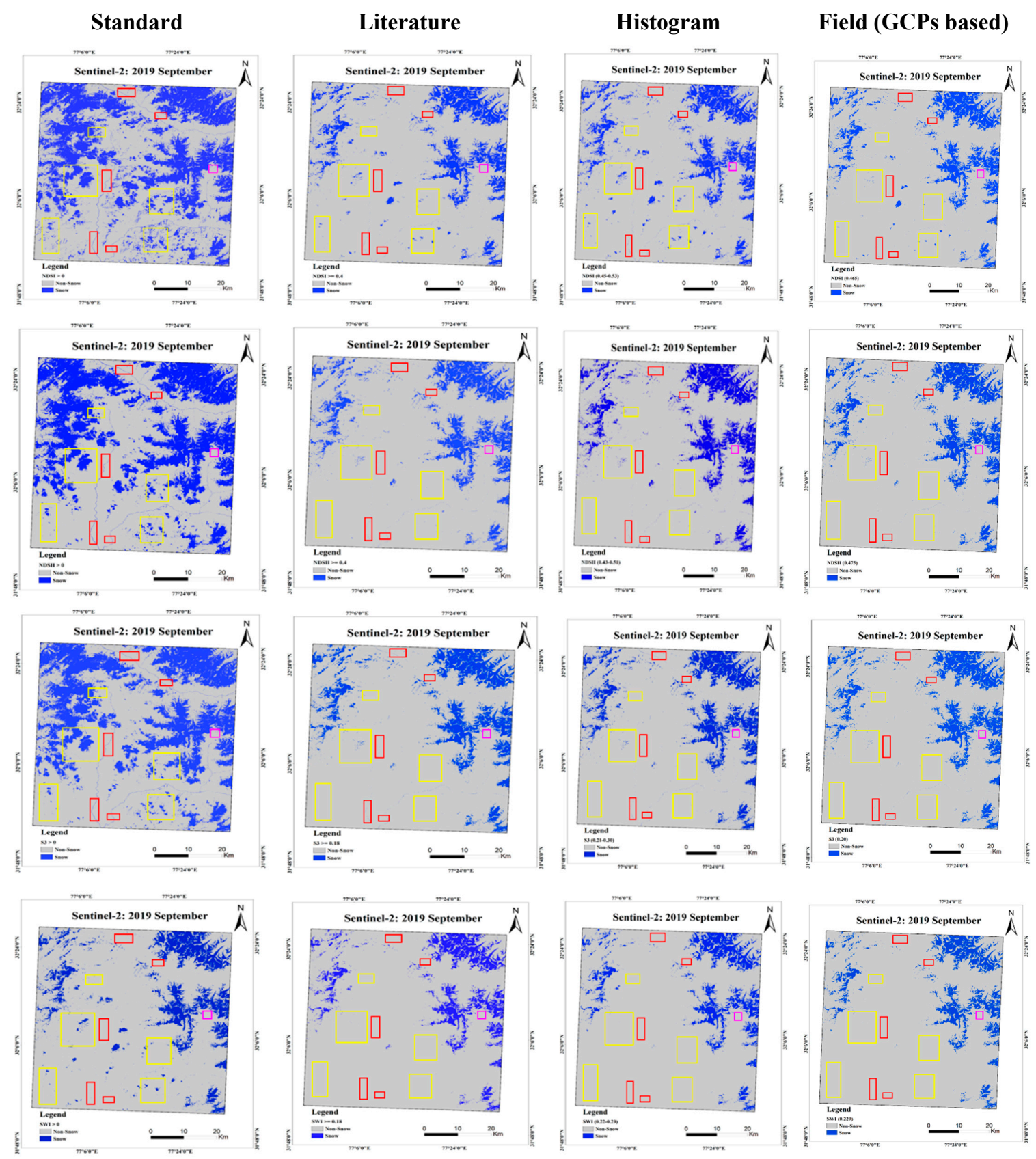

Figure 14. Snow classification output for different snow indices with the standard, literature, histogram, and GCPs driven thresholds for the September 2019 Sentinel-2 image.

In the accumulation months of March 2017 and March 2019 and ablation months of September 2017 and September 2019, Landsat-8 and Sentinel-2 satellite images were processed with all of the discussed snow indices, and the results are presented for visual assessment. Visual comparison of the standard, literature (fixed threshold), histogram, and GCPs driven indices, specifically with reference to clouds, flowing, and static water features, resulted in GCP driven indices being the optimal source of partitioning the image into the snow and non-snow classes. Together, the performance of the standard threshold $(>0)$ was the worst in the group while the literature and histogram driven indices were also unable to classify the image in snow and non-snow pixels accurately. Based on the visual inspection, all indices with the selected threshold seemed to depict different patterns. In the case of the NDSI, NDSII-1, and S3, in the red rectangles together, it can be witnessed that the flowing water features were continuously misclassified as snow in both the Landsat- 8 and Sentinel- 2 images for the accumulation 
period. In the ablation month of September, the performance of NDSI, NDSII-1, and S3 became more inaccurate because of the presence of clouds, flowing, and static water features for both the Landsat- 8 and Sentinel-2 images. S3 was more accurate in discriminating the snow and non-snow pixels in comparison to the NDSI and NDSII-1. Its performance of assessing the presence of flowing and static water features was much better, but some misclassified cloud pixels could continuously be seen in the ablation results. The results of the SWI was much better in comparison to the NDSI, S3, and NDSII-1. None of the snow/non-snow maps generated with SWI misclassified static or flowing water bodies and cloud pixels for both the accumulation and ablation period. Thus, the visual assessment of all the resultant snow/non-snow map results showed that SWI was best at delineating the snow feature for both the accumulation and ablation period.

In order to analyze how well these indices performed in the selected satellite images, we selected thirteen different types of cases, each referring to a specific type of feature and satellite image, as presented in Figure 15. Now, we discuss them one by one from the first case to last. Snow in the ablation period for the Landsat- 8 satellite is presented in the first row. The SWI was capable of discriminating the impact of mixed features and delineating snow with a higher contrast value. Snow in the ablation period for the Sentinel-2 satellite is presented in the second row. With the higher resolution of Sentinel-2 in comparison to Landsat-8, the performance of SWI, together with the other indices, was enhanced to discriminate other mixed features. Snow in the accumulation month for Landsat- 8 and the Sentinel-2 is presented in rows three and four, respectively. In the accumulation month, the accuracy of the indices was more clearly visible where S3 and SWI were able to map the pure snow pixels with higher accuracy in comparison to other indices. Flowing water features are presented next for the Landsat- 8 and Sentinel-2 satellites in rows five and six, respectively. The impact of the SWI was most accurately visible in the case of flowing water, where all of the other indices outperformed in detecting flowing water pixels in comparison to the SWI. Rows seven and eight, present the results for static water bodies for the Landsat- 8 and Sentinel-2 satellites, respectively. In the case of the Landsat- 8 static water, features were identified well with almost all of the selected indices. The NDSI continuously mixed water pixels with ice pixels, but, in the case of Sentinel-2, the performance of the SWI was a bit reduced for detecting standing water pixels. This is due to the use of the mean wavelength. Thresholding could improve the result and identification of static water bodies. Cloud features are presented next for the Landsat- 8 and Sentinel-2 satellites in rows nine and ten, respectively. None of the indices, except for the SWI, were capable of detecting cloud pixels in the selected image. SWI performed in both the case of Landsat- 8 , and Sentinel- 2 was best at removing the impact of cloud pixels. Vegetation cover in Landsat- 8 and for the Sentinel-2 is presented in rows eleven and twelve, respectively. Every index performed well in identifying the vegetation pixels. Debris cover in Landsat- 8 is presented in row number thirteen. The performance of NDSII-1, S3, and SWI was equally good and much better for the performance of the NDSI. Thus, after examining the results of all indices in the thirteen different cases with all possible feature classes and two selected satellite images, the performance of SWI was found to be best in comparison to all of the frequently used snow indices (NDSI, S3, and NDSII-1). 


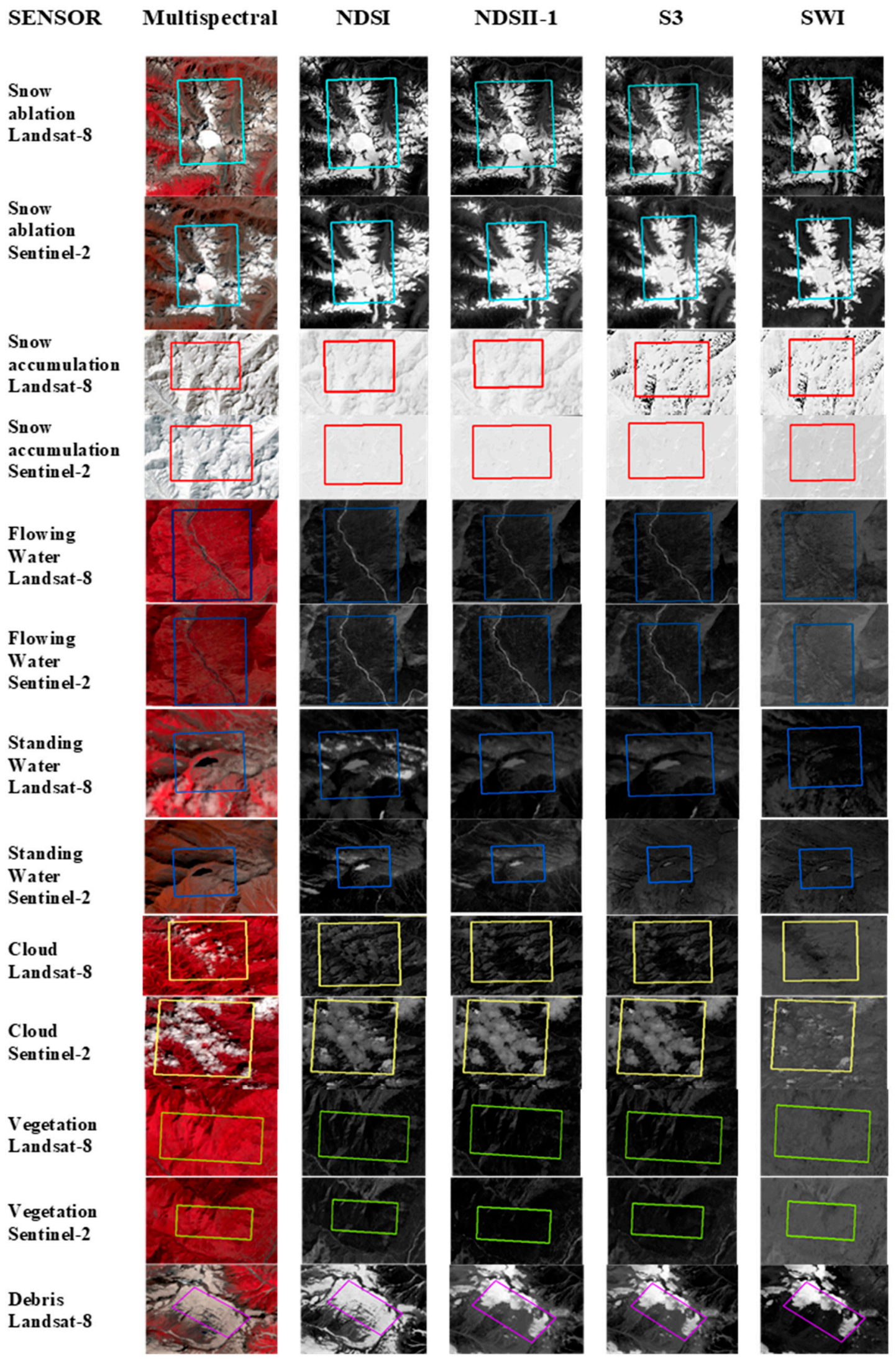

Figure 15. Comparison of the different snow indices (NDSI, NDSII-1, S3, and SWI) classification results for all possible mixed features selected with Landsat- 8 and Sentinel-2 satellite imagery. 


\subsection{Validation Using Spectroradiometer Observations}

The current section presents the results obtained after analysis and a comparison of the reflectance characteristics of clean snow and contaminated snow, vegetation, and water in the green, red, NIR, and SWIR bands along with their influence on the values of the indices using spectroradiometer observations. The spectral separability plots of features in the green, red, NIR, and SWIR wavelengths with respect to NDSI, S3, NDSII-1, and SWI using the spectroradiometer dataset are presented in Figures 16-19, respectively. From the spectroradiometer observations, we found that the reflectance for all types of snow, clean as well as mixed with soil, in the visible region extended in the range of $60-100 \%$ and the SWIR was found to be in the range of $0-15 \%$. For other classes such as vegetation and water reflectance, the visible range was between $0-15 \%$ and $0-20 \%$ in the SWIR wavelength. Instead, in the NIR region, reflectance was found to be in the range of $0-10 \%$ for water, $40-50 \%$ for vegetation, and $60-80 \%$ for clean as well soil mixed snow, as shown in Figures 18 and 19. From the reflectance characteristics of different classes in the green, red, NIR, and SWIR regions, we can interpret that, in the NIR region, snow, as well as other features, are highly separated from each other as compared to the SWIR region.
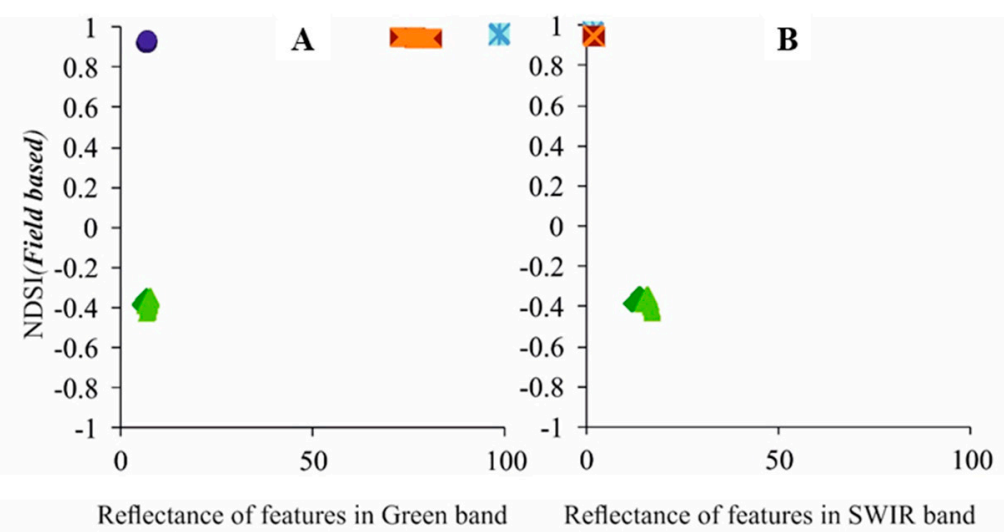

Legend: $\approx$ CleanSnow $₫$ Snowmixed with soil $\bullet$ Vegetation(Taxus baccata) $\triangle$ Vegetation(Shrubs) $\bullet$ Water

Figure 16. Reflectance of features in the green (A) and SWIR band using spectroradiometer observations for the NDSI (B).
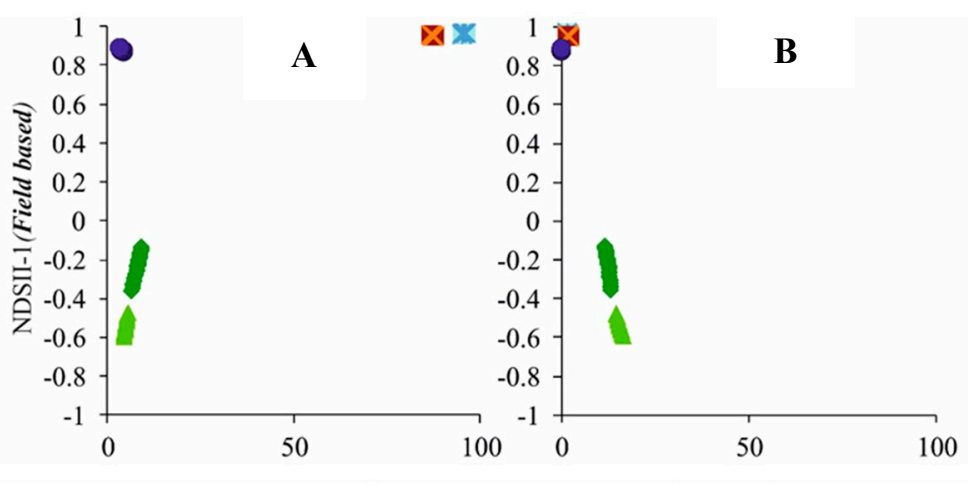

Reflectance of features in Red band Reflectance of features in SWIR band

Legend: $*$ CleanSnow $₫$ Snowmixed with soil $\bullet$ Vegetation(Taxus baccata) $\Delta$ Vegetation(Shrubs) $\bullet$ Water

Figure 17. Reflectance of features in the red (A) and SWIR band using spectroradiometer observations for the NDSII-1(B). 

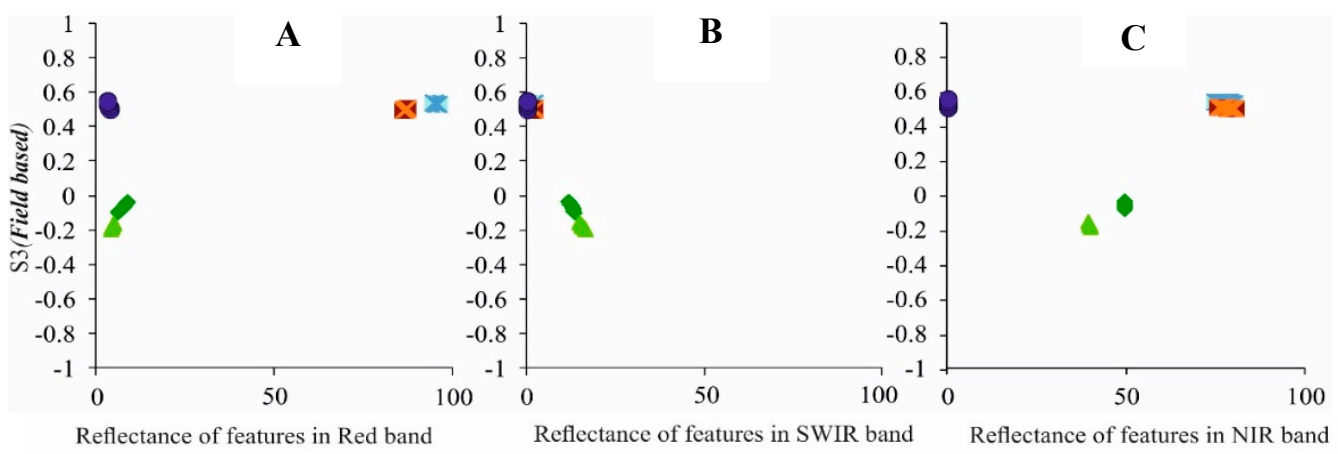

Legend: $\quad *$ CleanSnow

Snowmixed with soil

- Vegetation(Taxus baccata)

$\triangle$ Vegetation(Shrubs)

$\bullet$ Water

Figure 18. Reflectance of features in the green (A) SWIR (B) and NIR band using spectroradiometer observations for S3 (C).

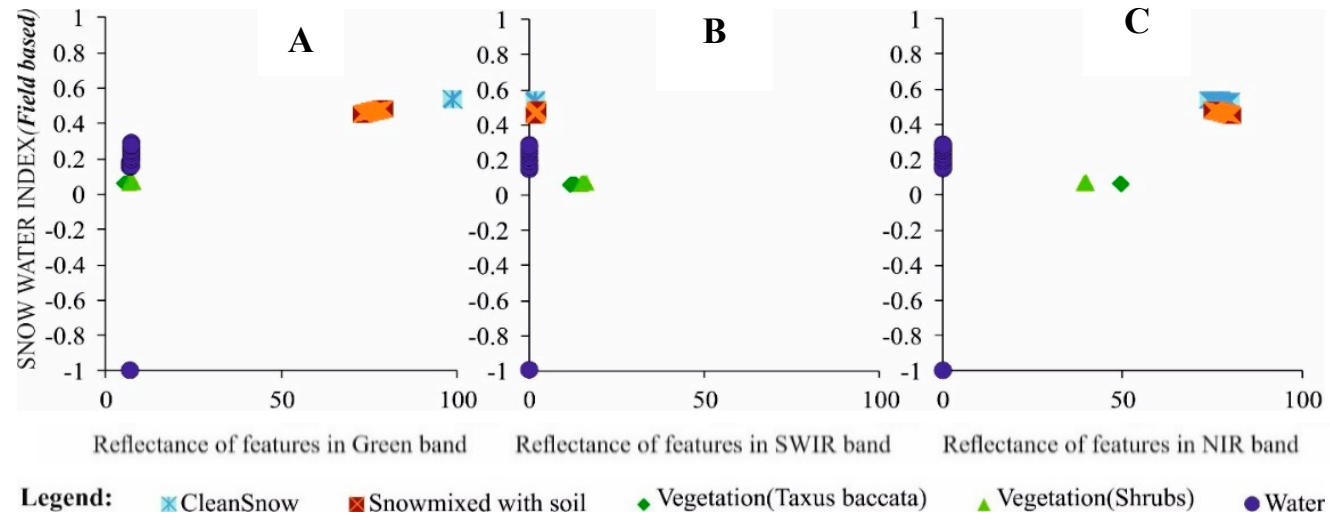

Figure 19. Reflectance of features in the green (A), SWIR (B), and NIR band using spectroradiometer observations for SWI (C).

In the present study, we computed the index values for different classes such as snow, soil mixed snow, vegetation, and water, and compared the separation of features in individual wavelengths with snow with respect to their index's values. The computed index values for all types of snow, clean as well as snow mixed with soil, for NDSI, S3, NDSII-1, and SWI are given in Table 5 In the case of vegetation, the measured value from all of the indices was less than zero or less when compared to the snow values in Table 5. Therefore, there was no ambiguity between the snow and vegetation. From the scatter plot given in Figures 16-19, we observed that water had a low reflectance in the visible and SWIR region when compared to snow. However, the computed index values from the NDSI, NDSII-1, and S3 were found very close or exactly the same as snow, except in the SWI exhibited in Table 5 and Figure 19.

Table 5. Spectro-radiometer reflectance (\%) for the green, red, NIR, SWIR bands and the NDSI, NDSII-1, S3 and SWI indices for different target features.

\begin{tabular}{ccccccccc}
\hline \multirow{2}{*}{ Target } & \multicolumn{7}{c}{ Spectro-Radiometer Reflectance (\%) } \\
\cline { 2 - 8 } & Green & Red & NIR & SWIR & NDSI & NDSII-1 & S3 & SWI \\
\hline Clean Snow & 98.33 & 95.10 & 77.20 & 02.10 & 00.96 & 00.95 & 00.53 & 00.53 \\
Snow mixed with soil & 78.70 & 87.10 & 77.70 & 02.50 & 00.93 & 00.93 & 00.25 & 00.47 \\
Vegetation (Shrubs) & 07.12 & 04.50 & 39.80 & 17.40 & -00.41 & -00.58 & -00.20 & 00.05 \\
Vegetation (Taxus & 06.45 & 07.30 & 49.50 & 14.15 & -00.36 & -00.31 & -00.09 & 00.06 \\
baccata) & 07.09 & 03.80 & 00.40 & 00.25 & 00.93 & 00.87 & 00.39 & 00.16 \\
Water & & & & & & & &
\end{tabular}




\subsection{Validation Using GCPS}

Statistical accuracy assessment parameters (user's accuracy (UA), producer's accuracy (PA), overall accuracy (OA), and kappa coefficient) were computed for all of the selected snow indices using ground control points acquired using field survey. The results are presented in Table 6. The UA and PA statistics of NDSI, S3, NDSII-1, and SWI represent a substantial commitment of these indices toward snow delineation. It can be seen that the overall accuracy of SWI was the maximum in the group of selected snow indices. The Kappa statistics show the correlation of the extracted snow pixels with ground observations (GCPs). Kappa statics of the SWI was 0.947, which was better than the NDSII-1, S3, and NDSI indices.

Table 6. Accuracy assessment based on the GCPs (Ground Control Points) for snow indices.

\begin{tabular}{ccccc}
\hline INDICES & UA & PA & OA & Kappa \\
\hline NDSII-1 & 0.90 & 0.79 & 0.85 & 0.747 \\
NDSI & 0.68 & 0.90 & 0.80 & 0.713 \\
S3 & 0.91 & 0.70 & 0.89 & 0.888 \\
SWI & 0.89 & 0.93 & 0.93 & 0.947 \\
\hline
\end{tabular}

\section{Conclusions}

Some of the most frequently used snow indices like the NDSI, S3, and NDSII-1 integrating visible, NIR, and SWIR wavelengths have significantly enhanced the ease and accuracy of snow cover estimation. However, snow and water have similar index values in the NDSI, NDSII-1, and S3. Therefore, a water mask is required to discriminate between water and snow pixels. The external dependency of the water mask affects the accuracy of the automated extraction of snow cover. To address this problem, a new snow index called the snow water index (SWI) was developed. The SWI provides a clear contrast between snow and other feature types including water bodies. Some of the major outcomes of the current study are as follows:

Results for the NDSI, S3, NDSII-1 show that these indices provide significant separation between snow and non-snow features except in the presence of water (static and flowing) and cloud cover.

Analysis of spectral observations collected for different features using spectroradiometer showed that in the NIR region, reflectance occurred in the range of $0-10 \%$ for water, $40-50 \%$ for vegetation, and $60-80 \%$ for clean as well soil mixed snow. This implies that in the NIR band, all of the features were clearly separated from each other, and the limitations of NDSI, S3, and NDSII- 1 can be improved by using the absorptive property of water in this band.

The SWI was developed with the combination of the NIR and SWIR bands, which acts as a water mask and reduces the influence of water on snow.

The standard, literature, and histogram-based thresholds selected in the study for all snow indices were able to extract most of the snow pixels (i.e., high PA), but with many misclassified non-snow pixels (i.e., low UA). Based on visual and field observation-based assessments, these standard, literature, and histogram-based thresholds are not useful in deriving a snow cover map in a scene with diverse impure pixels belonging to different features.

The GCPs based threshold improved the delineation capability in most cases with a higher OA and higher kappa coefficient. With the GCP based threshold, SWI was best at extracting snow pixels and rejecting the other impure pixels of other features, whereas S3 was capable of identifying the impure pixels of water and cloud cover up to some extent, but was unable to remove their impact over pure snow pixels completely. NDSII- 1 and NDSI outperformed most in the group.

An accurate estimation of the spatial extent of snow cover is vital to maintain the ecological balance and is also useful for various hydrological applications. It is recommended that for real-life implementation, the selection of a specific snow index requires care with caution by thoroughly reviewing and examining the advantages and constraints of all the available snow indices and 
then integrating them for application in a selected study area with specific terrain conditions and environmental characteristics. The performance of the NDSI, S3, and NDSII-1 in this study provides evidence of the deleterious effect of overlapped classes, especially water in snow cover. Inaccurate estimation of snow is also evident in the ground data and multispectral sensor. The proposed SWI index takes advantage of the multispectral repose of unwanted features and generates artifact-free snow cover maps. The accuracy assessment establishes SWI as a promising index for snow cover estimation and mapping.

Author Contributions: Conceptualization, A.D., A.G.; Formal analysis, A.D., A.G.; Funding acquisition, A.G.; Investigation, A.G.; Project administration, A.G.; Writing—original draft, A.D., A.G., S.J.

Funding: This research received no external funding.

Acknowledgments: The authors would like to acknowledge Indian Institute of Technology, Roorkee, India for providing necessary infrastructure facilities. The authors also acknowledge Ministry of Human Resource Development India for providing all the necessary support. Our Sincere thanks to H.S. Negi, SASE India for sharing few of the field observations. The authors also thank to Rajeev Ranjan, JRF (CoEDMM) for his help in data pre-processing. The authors also thank the anonymous reviewer for their valuable suggestions.

Conflicts of Interest: The authors declare no conflict of interest.

\section{References}

1. Aggarwal, K.C.; Kumar, V.; Dass, T. Snowmelt run-off for a catchment of Beas basin. In Proceedings of the First National Symp. on Seasonal Snow Cover, SASE, Manali, India, 28-30 April 1983; pp. 43-63.

2. Jain, S.K.; Goswami, A.; Saraf, A.K. Snowmelt runoff modelling in a Himalayan basin with the aid of satellite data. Int. J. Remote Sens. 2010, 31, 6603-6618. [CrossRef]

3. SAC \& MoEF. Snow and Glaciers of the Himalayas: Inventory and Monitoring (Work Carried out by Space Applications Centre, ISRO in Collaboration with other Organisations); Discussion Paper II; Space Applications Centre, ISRO, Ahmedabad and Ministry of Environment and Forests: New Delhi, India, 2010.

4. SAC 2011. Snow and Glaciers of the Himalayas (Study Carried out Under the Joint Project of Ministry of Environment and Forests and Department of Space, Government of India); Space Applications Centre, ISRO: Ahmedabad, India, 2011; p. 258.

5. Bonan, G. Ecological Climatology, Concepts and Applications; Cambridge University Press: New York, NY, USA, 2002.

6. Foster, J.L.; Chang, A.T.C. Snow cover. In Atlas of Satellite Observations Related to Global Change; Gurney, R.J., Parkinson, C.L., Foster, J.L., Eds.; Cambridge University Press: Cambridge, UK, 1993; pp. 361-370.

7. Jain, S.K.; Goswami, A.; Saraf, A.K. Accuracy assessment of MODIS, NOAA and IRS data in snow cover mapping under Himalayan conditions. Int. J. Remote Sens. 2008, 29, 5863-5878. [CrossRef]

8. Klein, A.G.; Hall, D.K.; Nolin, A.W. Development of a prototype snow albedo algorithm for the NASA MODIS instrument. In Proceedings of the 57th Eastern Snow Conference, New York, NY, USA, 17-19 May 2000; pp. 15-17.

9. Zhao, H.; Fernandes, R.; Wang, X.; Key, J.; Qu, X.; Hall, A. Controls on Northern Hemisphere snow albedo feedback quantified using satellite Earth observations. Geophys. Res. Lett. 2009, 36. [CrossRef]

10. Lu, S.; Oki, K.; Omasa, K. Mapping snow cover using AVHRR/NDVI 10-day composite data. J. Agric. Meteorol. 2005, 60, 1215-1218. [CrossRef]

11. Monson, R.K.; Burns, S.P.; Williams, M.W.; Delany, A.C.; Weintraub, M.; Lipson, D.A. The contribution of beneath-snow soil respiration to total ecosystem respiration in a high-elevation, subalpine forest. Glob. Biogeochem. Cycles 2003, 20. [CrossRef]

12. Isard, S.A.; Schaetzl, R.J.; Andresen, J.A. Soils cool as climate warms in the great lakes region: 1951-2000. Ann. Assoc. Am. Geogr. 2007, 97, 467-476. [CrossRef]

13. Darmody, R.G.; Thorn, C.E.; Schlyter, P.; Dixon, J.C. Relationships of Vegetation Distribution to Soil Properties in Kärkevagge, Swedish Lapland. Arct. Antarct. Alp. Res. 2004, 36, 21-32. [CrossRef]

14. Löffler, J. Snow cover dynamics, soil moisture variability and vegetation ecology in high mountain catchments of central Norway. Hydrol. Process. 2005, 19, 2385-2405. [CrossRef] 
15. Potts, H.L. A photographic survey method of forecasting runoff. Trans.-Am. Geophys. Union 1944, 25, $153-194$. [CrossRef]

16. Miller, D.H. Snow Cover Depletion and Runoff. Snow Hydrology; USA Army Corps of Engineers: Portland, ME, USA, 1953.

17. Namias, J. Snowfall over eastern United States: Factors leading to its monthly and seasonal variations. Weatherwise 1960, 13, 238-247. [CrossRef]

18. Namias, J. Influences of abnormal surface heat sources and sinks on atmospheric behaviour. In Proceedings of the Int. Symp. on Numerical Weather Prediction, Tokyo, Japan, March 1962; pp. 615-627.

19. Lamb, H.H. Climate, Present, Past and Future; Methuen and Co. Ltd.: London, UK, 1972; Volume 1.

20. Kukla, G.J.; Kukla, H.J. Increased Surface Albedo in the Northern Hemisphere: Did satellites warn of the weather troubles of 1972 and 1973. Science 1974, 183, 709-714. [CrossRef]

21. Dickson, R.R.; Namias, J. North American influences on the circulation and climate of the North Atlantic sector. Mon. Weather Rev. 1976, 104, 1255-1265. [CrossRef]

22. Kavzoglu, T.; Colkesen, I. A kernel functions analysis for support vector machines for land cover classification. Int. J. Appl. Earth Obs. Geoinf. 2009, 11, 352-359. [CrossRef]

23. Singh, P.; Singh, V.P. Snow and Glacier Hydrology; Kluwer Academic Publishers: Dordrecht, The Netherlands, $2011 ;$ p. 742.

24. O'brian, H.W.; Munis, R.H. Red and Near-Infrared Spectral Reflectance of Snow; Research Report 332; U.S. Army Cold Regions Research and Engineering Laboratory: Hanover, NH, USA, 1975.

25. Warren, S.G.; Wiscombe, W.J. A model for the spectral albedo of snow. I: Pure snow. J. Atmos. Sci. 1980, 37, 2712-2733. [CrossRef]

26. Warren, S.G.; Wiscombe, W.J. A model for the spectral albedo of snow. II: Snow containing atmospheric aerosols. J. Atmos. Sci. 1980, 37, 2734-2745. [CrossRef]

27. Warren, S.G. Optical properties of snow. Rev. Geophys. 1982, 20, 67-89. [CrossRef]

28. Zeng, Q.; Cao, M.; Feng, X.; Liang, F.; Chen, X.; Sheng, W. A study of spectral reflection characteristics for snow, ice and water in the north of China. Hydrol. Appl. Remote Sens. Remote Data Transm. 1984, 145, 451-462.

29. Hall, D.K.; Riggs, G.A.; Salomonson, V.V. Development of methods for mapping global snow-cover using moderate resolution spectroradiometer data. Remote Sens. Environ. 1995, 54, 127-140. [CrossRef]

30. Williams, R.S., Jr.; Hall, D.K. Glaciers. In Atlas of Satellite Observations Related to Global Change; Gurney, R.J., Foster, J.L., Parkinson, C.L., Eds.; Cambridge University Press: New York, NY, USA, 1993; pp. 401-422.

31. Kulkarni, A.V.; Rathore, B.P.; Singh, S.K. Monitoring of seasonal snow cover in the Western Himalaya. In Proceedings of the International Workshop on Snow, Ice, Glaciers and Avalanches, Mumbai, India, 7-9 January 2008; pp. 85-92.

32. Köning, M.; Sturm, M. Mapping snow distribution in the Alaskan Arctic using aerial photography and topographic relationships. Water Resour. Res. 1998, 34, 3471-3483. [CrossRef]

33. Foppa, N.; Seiz, G. Inter-annual variations of snow days over Switzerland from 2000-2010 derived from MODIS satellite data. Cryosphere 2012, 6, 331-342. [CrossRef]

34. Singh, P.; Haritashya, U.K.; Singh, V.P. Encyclopedia of Snow, Ice and Glaciers; Springer: Berlin, Germany, 2011; pp. 245-256.

35. Gupta, R.P.; Haritashya, U.K.; Singh, P. Mapping dry/wet snow cover in the Indian Himalayas using IRS multispectral imagery. Remote Sens. Environ. 2005, 97, 458-469. [CrossRef]

36. Kour, R.; Patel, N.; Krishna, A.P. Assessment of relationship between snow cover characteristics (SGI and SCI) and snow cover indices (NDSI and S3). Earth Sci. Inform. 2015, 8, 317-326. [CrossRef]

37. Sharma, R.C.; Tateishi, R.; Hara, K. A new water-resistant snow index for the detection and mapping of snow cover on a global scale. Int. J. Remote Sens. 2016, 37, 2706-2723. [CrossRef]

38. Shimamura, Y.; Izumi, T.; Matsumaya, H. Evaluation of a useful method to identify snow-covered areas under vegetation-comparisons among a newly proposed snow index, normalized difference snow index and visible reflectance. Int. J. Remote Sens. 2006, 27, 4867-4884. [CrossRef]

39. Xiao, X.; Shen, Z.; Qin, X. Assessing the potential of VEGETATION sensor data for mapping snow and ice cover: A normalized difference snow and ice index. Int. J. Remote Sens. 2001, 22, 2479-2487. [CrossRef]

40. Keshri, A.; Shukla, A.; Gupta, R.P. ASTER ratio indices for supraglacial terrain mapping. Int. J. Remote Sens. 2009, 30, 519-524. [CrossRef] 
41. Sibandze, P.; Mhangara, P.; Odindi, J.; Kganyago, M. A comparison of Normalised Difference Snow Index (NDSI) and Normalised Difference Principal Component Snow Index (NDPCSI) techniques in distinguishing snow from related land cover types. S. Afr. J. Geomat. 2014, 3, 197-209. [CrossRef]

42. Dozier, J.; Schneider, S.R.; McGinnis, D.F. Effect of grain size and snowpack water equivalence on visible and near-infrared satellite observations of snow. Water Resour. Res. 1981, 17, 1213-1221. [CrossRef]

43. Dozier, J. Snow reflectance from Landsat-4 thematic mapper. IEEE Trans. Geosci. Remote Sens. 1984, 3, 323-328. [CrossRef]

44. Dozier, J. Spectral signature of alpine snow cover from the Landsat Thematic Mapper. Remote Sens. Environ. 1989, 28, 9-22. [CrossRef]

45. Hall, D.K.; Chang, A.T.C.; Foster, J.L. Nimbus-7 SMMR derived global snow cover parameters. Ann. Glaciol. 1987, 9, 39-44.

46. Bronge, L.B.; Bronge, C. Ice and snow-type classification in the Vestfold Hills, East Antarctica, using Landsat-TM data and ground radiometer measurements. Int. J. Remote Sens. 1999, 20, 225-240. [CrossRef]

47. Paul, F.; Huggel, C.; Kääb, A. Combining satellite multispectral image data and a digital elevation model for mapping debris-covered glaciers. Remote Sens. Environ. 2004, 89, 510-518. [CrossRef]

48. Stillinger, T.; Roberts, D.A.; Collar, N.M.; Dozier, J. Cloud masking for Landsat 8 and MODIS Terra over snow-covered terrain: Error analysis and spectral similarity between snow and cloud. Water Resour. Res. 2019, 55, 6169-6184. [CrossRef]

49. Zi, Y.; Xie, F.; Jiang, Z. A cloud detection method for Landsat 8 images based on PCANet. Remote Sens. 2018, 10, 877. [CrossRef]

50. Dutra, V.A.B.; Tavares, P.A.; Ribeiro, H.M.C. Analysis of cloud condition on Sentinel-2 MSI and Landsat-8 OLI images of a public supply lake in Belém-Pará-Brazil. Ambiente Agua-An Interdiscip. J. Appl. Sci. 2019, 14, 1-11. [CrossRef]

51. Sun, L.; Mi, X.; Wei, J.; Wang, J.; Tian, X.; Yu, H.; Gan, P. A cloud detection algorithm-generating method for remote sensing data at visible to short-wave infrared wavelengths. ISPRS J. Photogramm. Remote Sens. 2017, 124, 70-88. [CrossRef]

52. Joseph, G.; Navalgund, R.R. Remote sensing-physical basis and its evolution. In Glimpses of Science in India; National Academy of Sciences: Allahabad, India, 1991; pp. 357-385.

53. Hall, D.K.; Riggs, G.A.; Salomonson, V.V. A snow index for the Landsat thematic mapper and moderate resolution imaging spectroradiometer. In Proceedings of the IGARSS, 94-1994 IEEE International Geoscience and Remote Sensing Symposium, Pasadena, CA, USA, 8-12 August 1994; Volume 4, pp. 1942-1944.

54. Kulkarni, A.V.; Srinivasulu, J.; Manjul, S.S.; Mathur, P. Field based spectral reflectance studies to develop NDSI method for snow cover monitoring. J. Indian Soc. Remote Sens. 2002, 30, 73-80. [CrossRef]

55. Kulkarni, A.V.; Singh, S.K.; Mathur, P.; Mishra, V.D. Algorithm to monitor snow cover using AWiFS data of RESOURCESAT-1 for the Himalayan region. Int. J. Remote Sens. 2006, 27, 2449-2457. [CrossRef]

56. Landsat-8 and Sentinel-2. Available online: http://earthexplorer.usgs.gov (accessed on 15 September 2019).

57. Negi, H.S.; Kulkarni, A.V.; Semwal, B.S. Study of contaminated and mixed objects snow reflectance in Indian Himalaya using spectroradiometer. Int. J. Remote Sens. 2009, 30, 315-325. [CrossRef]

58. Hall, D.K.; Foster, J.L.; Verbyla, D.L.; Klein, A.G.; Benson, C.S. Assessment of snow-cover mapping accuracy in a variety of vegetation-cover densities in central Alaska. Remote Sens. Environ. 1998, 66, 129-137. [CrossRef]

59. Hall, D.K.; Riggs, G.A.; Salomonson, V.V.; Barton, J.S.; Casey, K.; Chien, J.Y.L.; DiGirolamo, N.E.; Klein, A.G.; Powell, H.W.; Tait, A.B. Algorithm Theoretical Basis Document (ATBD) for the MODIS Snow and Sea Ice-Mapping Algorithms; Nasa Gsfc: Greenbelt, MD, USA, 2001; p. 45.

60. Hall, D.K.; Riggs, G.A.; Salomonson, V.V.; DiGirolamo, N.E.; Bayr, K.J. MODIS snow-cover products. Remote Sens. Environ. 2002, 83, 181-194. [CrossRef]

61. Negi, H.S.; Singh, S.K.; Kulkarni, A.V.; Semwal, B.S. Field-based spectral reflectance measurements of seasonal snow cover in the Indian Himalaya. Int. J. Remote Sens. 2010, 31, 2393-2417. [CrossRef]

62. Salomonson, V.V.; Appel, I. Estimating fractional snow cover from MODIS using the normalized difference snow index. Remote Sens. Environ. 2004, 89, 351-360. [CrossRef]

63. Motoya, K.; Yamazaki, T.; Yasuda, N. Evaluating the spatial and temporal distribution of snow accumulation, snowmelts and discharge in a multi basin scale: An application to the Tohoku Region, Japan. Hydrol. Process. 2001, 15, 2101-2129. [CrossRef] 
64. Motoya, K. Spectral characteristic-based vegetation and snow indices on various surfaces in the Airborne Multi-Spectral Scanner (AMSS) two-altitude observation in 2001. J. Jpn. Soc. Hydrol. Water Resour. 2003, 16, 408-419. [CrossRef]

65. Shimamura, Y.; Izumi, T.; Nakayama, D.; Matsumaya, H. Estimation of snow water equivalent and snowmelt water using the snow index -A case study in the Kurobe basin. J. Jpn. Soc. Hydrol. Water Resour. 2003, 16, 331-348. [CrossRef]

66. Tilahun, A.; Islam, Z. Google Earth for Land Use Land Cover Change Detection in the Case of Gish Abbay Sekela, West Gojjam, Amhara State, Ethiopia. Int. J. Adv. Remote Sens. GIS Geogr. 2015, 3, 80-87.

67. Congalton, R.G. A Review of Assessing the Accuracy of Classifications of Remotely Sensed Data. Remote Sens. Environ. 1991, 37, 35-46. [CrossRef]

68. Anderson, J.; Hardy, E.; Roach, J.; Witmer, R. A Land Use Classification System for Use with Remote-Sensor Data; USGS Circular 671; US Geological Survey: Washington, DC, USA, 1972. [CrossRef]

69. Jenness, J.; Wynne, J.J. Kappa Analysis (kappa_stats.avx) Extension for ArcView 3.x. Jenness Enterp. 2007.

(C) 2019 by the authors. Licensee MDPI, Basel, Switzerland. This article is an open access article distributed under the terms and conditions of the Creative Commons Attribution (CC BY) license (http://creativecommons.org/licenses/by/4.0/). 